\title{
Index der Institutionen und Organisationen
}

Nachgewiesen werden alle Behörden, Dienststellen, Parteien, Verbände, Vereine, Firmen und sonstigen juristischen Personen mit eindeutiger Bezeichnung, jedoch wurden vorkommende unterschiedliche Namen - auch bei Behörden mit derselben Funktion - vereinheitlicht (z. B. „ultusministerium“ statt ,Staatsministerium für ...“, Reichspropagandaministerium statt Reichsministerium für Volksaufklärung und Propaganda). Behördenbezeichnungen im subjektiven Stil wurden in objektive Bezeichnungen umgewandelt, wenn diese ebenfalls gebräuchlich waren (Reichsministerium statt Reichsminister). Von Ländernamen abgeleitete Adjektiva (badisch, bayerisch) stehen grundsätzlich an zweiter Stelle. Kollektivbezeichnungen für Verwaltungszweige (Polizei, Erbhofgerichte) oder Organisationen (Gewerkschaften, Jugendverbände) sind im Sachindex berücksichtigt.

Abgeordneten- und Herrenhaus, preuB. 13

Abschnittskommando Baden-Baden des Generalkommandos V 444

Abteilung für Kraftverkehr und Strabenwesen des Reichsverkehrsministeriums 369

Abteilung Wasser- und Schiffahrtsverwaltung der Regierung Aurich 403

Abteilung Wehrmacht der DAF 449

Abteilung Wehrmachtverlustwesen des OKW 431

Abteilung Wiesbaden des Generalinspektors für das deutsche Straßenwesen 373

Abteilungen Fremde Heere West und Ost des OKH 433

Abteilungen für Anfechtungssachen auf dem Gebiet der Besitz- und Verkehrssteuern 249

Abteilungen für Rechtsforschung und -gestaltung der ADR 186

Abwehrabteilung des Reichskriegsministeriums 429

Abwehrbeauftragter der SS 117

Abwehmebenstelle Bremen 448

Abwehrstelle VII, München 448

AbwickJungsstelle des Reichskommissars für die Ablösung der Reichsanleihen alten Besitzes 327

Adjutantur des Führers 4, 456, 457

Adjutanturen der Wehrmacht beim Führer 2. 4, 427

Admiral der Kampfverbände 236

Adolf-Hitler-Bad-Pyrmont-Stiftung 30

Adolf-Hitler-Schule Köln-Aachen, Königswinter 352, 475

Adolf-Hitler-Schule Sonthofen 475

Adolf-Hitler-Schule Weimar 475

Adolf-Hitler-Schule Westmark 475

Adolf-Hitler-Stiftung für junge Architekten und Städtebauer 63
Aerodynamische Versuchsanstalt Götringen 438

Aeronautisches Observatorium. Lindenberg/Brandenburg 439

Ärteverein Bonn 281

Ahnenerbe s. Lehr- und Forschungsgemeinschafi

Ahnenerbe-Verlag 116

Ahnentafelamt der SS 119

Akademie Braunsberg 266

Akademie der Arbeit. Frankfurt 283

Akademie der Wissenschaften Göttingen 306

Akademie der Wissenschaften Heidelberg 269. 305

Akademie der Wissenschaften München 14. 267, 306

Akademie für Deutsches Recht 8. 186, 295. 336. 378

Akademie für Jugendführung der HJ 271

Albert-Ludwigs-Universität s. Universität Freiburg

Alemannisches Institut Freiburg 284

Alldeutscher Verband 157. 159

Allgemeine Electricitätsgesellschaft AEG 437

Allgemeine Elsässische Bankgesellschafi 332

Allgemeine Ortskrankenkasse Darmstadt 253

Allgemeiner Deutscher Gewerkschafisbund (ADGB) 123

Allgemeines Heeresamt im OKH 434

Allgemeines Luftamt 438

Algemeines Wehrmachtamt im OKW 430

Allod - Eigenheim- und Kleinsiedlung GmbH 119

Amt Ausland/Abwehr im OKW 42, 429

Amt für deutsche Roh- und Werkstoffe 358 , 377

Amt für kriegswichtigen Einsatz, Hamburg 353

Amt für Leibesübungen der SS 117

Amt für Rechtsbetreuung des NSRB 518 
Amt für Sippenforschung der NSDAP 64 459

Amt Informarion der DAF 509

Amt MIL des RSHA 125

Amt Rosenberg 421, 460, 462, 466, 475. 487

Amtliche Deutsche Ein- und Rückwandererstelle Bozen 174

Amtsgericht Passau 215

Amtsgruppe Maschinelles Berichtswesen 362

Amtsverwaltung Halle/Westf. 141

Amtsverwalnung Lieberhausen 148

Anerbengerichte s. Erbhofgerichte

Anmeldestelle fur Auslandsschulden 347

Ansiedlungsstäbe Kaven und Shitomir 174

Anthroposophische Gesellschaft 159

Antikomintern e. V. 262, 308

Apollinaris Brunnen A.G. 121

Apothekergerichtshof 257

Arado-Flugzeugwerke 437

Aubeiter-Sängertund 313

Arbeiter-Samariter-Bund 31, 59

Arbeiterwohlfahr 90

Arbeitsamt

- Aalen 424

- Ahien (Westfajen) $4 i 4$

- Ahrweiler 414

- Arnsberg 422

- Bad Mergentheim 424

- Balingen 424

- Bamberg 108

- Bassum 422

- Berlin-Mitte 414

- Bestwig 422

- Biberach an der RiB 424

- Bielefeld 414

- Bochum 422

- Boturop 414

- Bruchsal 414

- Celle 422

- Cham 425

- Deggendorf 414

- Detmold 414

- Dortmund 414

- Dïsseldorf 415

- Emden 422

- Erkelenz 423

- Eschweiler 423

- Esslingen 424

- Freising 413, 415

- Fulda 423

- Gelsenkirchen 415

- Göppingen 424

- Hagen 423

- Hamm 423

- Heilbronn 424

- Helmstedt 422
Arbeitsamt (Forts.)

- Herford 415

- Hof 425

- Idar-Oberstein 415

- Iseriohn 415

- Kaiserslautern 425

- Kamen 423

- Kartsruhe 424

- Kempten 415

- Korbach 423

- Landaw 425

- Leer 422

- Limburg 424

- Lippstadi 415, 422

- Lörrach 415

- Ludwigsburg 424

- Ludwigshafen 415

- Lüdenscheid 423

- Lünen 415

- Mainz 424

- Mannheim 424

- Marburg 423

- Marktred witz 108, 425

- Mayen 415

- Memmingen 415

- Moers 423

- Nagold 424

- Neumünster 416

- Neunkirchen (Saar) 416

- Niederlahnstein 424

- Nordhorn 422

- Nürnberg 424

- Offenburg 424

- Osnabrück 95

- Paderborn 416

- Pforzheim 424

- Pirmasens 425

- Rastar 424

- Ravensburg 424

- Recklinghausen 414, 423

- Rheine 414

- Rosenheim 416

- Rottweil 424

- Schwäbisch Gmünd 424

- Schwäbisch Hall 424

- Schwandorf 416

- Siegen 423

- Sigmaringen 424

- Soest 416

- Solingen 413

- Stade 416

- Stadthagen 422

- Straubing 416

- Sturgar 424

- Treysa 423

- Ulm 424

- Velbert 413 
Arbeitsamt (Forts.)

- Watenstedt-Salzgitter 416

- Wuppertal 413.416

ArbeitsausschuB Rationalisierung und Werkstättenausbau der Reichsbahn 363

Arbeitseinsatzstab Graf Spreti 415

Arbeitserziehungslager

- Breitenau 153

- Bremen-Farge 153

- Essen-Mülheirn 137

- Frankfurt-Heddernheim 153

- Hallendorf 153

- Hamburg-Wilheimsburg 153

- Hirzenhain 153

- Hückelhoven 153

- Hunswinkel bei Lüdenscheid 137, 154

- Lahde 154

- Nordmark 154

- Oberndorf-Astaig 154

- Recklinghausen 137

- Rudersberg 154

- Sandbostel 154

- Steinbergen 154

Arbeitsgauführung W 420

Arteitsgebiet für Industrielle Fette im Vierjahresplan 377

Arbeitsgemeinschaft für deutsche Wehrverstärkung 284

Arbeitsgemeinschaft für Wohlfahrtspflege. thein. 76

Arbeitsgemeinschaft nationalsozialistischer Studentinnen (ANST) 504, 507

Arbeitsgemeinschaft Raumforschung 296

Arbeitsgemeinschaft zur Förderung landwinschafulichen Bauwesens 365

Arbeitsgemeinschaften für gemeindliche Kulturpflege 63,75

Arbeitsgericht

- Aalen 250

- Bad Mergentheim 250

- Balingen 250

- Detmold 250

- Dillingen 251

- Erding 251

- Esslingen 251

- Freiburg 251

- Fulda 251

- Hagen 251

- Hamm 251

- Karlsruhe 251, 257

- Kemnath 251

- Landau 251

- Lörrach 251

- Ludwigshafen 251

- Lübeck 251

- Neuwied 25I

- Nidda 251
Atbeitsgericht (Forts.)

- Rastar 252

- Rosenheim 252

- Schwäbisch Hall 252

- Traunstein 252

- Tübingen 252

Arbeitshaus

- Bayreuth-St.Georgen 191

- Kislau 194

- Rebdorf 195

- Vaihingen 70, 196

Arbeitskammer Schwaben 514

Arbeitskommando "Berta“ des Konzentrationslagers Buchenwald 133

Arbeitskommando Gaggenau des Sicherungs. lagers Vortruck-Schirmeck 133

Arbeitskommando Gandersheim-Brunshausen des Konzentrationslagers Buchenwald 133

Arbeitskreis Schule - Elternhaus - HJ 81

Arbeitslager für Juden Paderborn 141

Arbeitsstab fîr die Preisfestsetzung bei Konsumgitiern 380

Arbeitsstelle für deutsche Musik im Ausland 176

Asteitswissenschaftliches Institut der DAF 512,513

Archäologisches Institut des Deutschen Reiches 47, 283, 294, 338

Architekt für die Neugestaltung der Hansestadt Hamburg 353

Archiv für Zeitgeschehen, Hannover 487

Archiv für Zeitgeschichte und Publizistik 475

Archiv zur Rheinlandbesetzung 36

Archivabteilung des preuBischen Staatsministeriums 12

Archivkommission des AA 47

Armeemuseum, bayer. 268

Armeeoberkommandos 47, 435, 440

Attaché-Abteilungen des OKH, OKM und OKL 439

Auferstehungsgemeinde 226

Auffanglager Eitorf 159

AufklärungsausschuB Hamburg-Bremen 315 , 430

Auslandabteilung des Wehrmachtưhrungsamies 429

Auslands- und Volkstumsamt der Reichsjugendfithrung 498

Auslands-Organisation der DAF 510

Auslands-Organisation der NSDAP 44, 177. 186, 280, 315, 472

Auslandsabteilung der ADR 186

Ausiandsamt der Dozentenschaft 283

Auslandsbriefprifstellen Berlin. Hamburg, Köln, München und Wien 408

Auslandsdeutsche Frauenschaft 501 
Auslandshochschule der Universität Berlin 275

AusschuB für Genossenschafisrecht der ADR 378

AuBenabteilung des Rechnungshofes des Deutschen Reiches

- Hamburg 29

- Karlssuhe 336, 338, 339

- München 339

AuBenhandelsamt der Auslands-Organisation 472

AuBenhandelsstelle

- Baden und Westmark 383

- Niederthein 384

- Nordwestfalen und Ruhrgebiet 384

AuBenlager Dalum des Konzentrationslagers Neuengamme 132

AuBenlager Mühldorf I des Konzentrationslagers Dachau 131

AuBenpolitisches Amt der NSDAP 466, 468

AuBenpolitisches Schulungshaus der NSDAP 468

Auswärtiges Amt 37-50, 176, 261, 275, 276. $280,315,317,325,336,383,430$

Auswanderberatungsstelle

- Karlsrube 15

- Bremen 176

- Köln 78, 83, 143, 176

- Münster 176

Auswertungsstelle der technischen und wirtschafulichen Weltfachpresse e. V. 266

Badenwerk 331

Baltisches Institut Thorn 178

Bank, Badische 332

Bank. Württembergische 9

Bankverein für Nordwestdeutschland 344

Bau- und Finanzdirektion Berlin, preuB. 353

Bauabteilungen für die Reichsautobahnen 403

Baubeauftragter beim Reichsverteidigungskommissar Köln-Aachen 352

Baubevollmächtigter beim Reichsverteidjgungskommissar Westmark 352

Baubüro Speer 351

Bauleitung der NSDAP 463

Bauschule Holmminden 271

Bavaria-Filmkunst 319

Bayerische Motorenwerke BMW 437

BDM 73, 475, 498

- Haushaltungsschule Cham 106

- Obergauführung Köln-Aachen 500

- Obergaufuhrung Schwaben 500

- Obergaufihrung Württemberg 501

- Werk „Glaube und Schönheit“ 498

Beaufuagte der NSDAP 32, 91, 112
Beauftragte des Reichskommissars für Festigung deutschen Volkstums 174

Beauftragte für die Bauwirtschaft bei den Reichsverteidigungskommissaren 352

Beaufuragter des Führers für die Überwachung der gesamten geistugen und weltanschaulichen Schulung und Erziehung der NSDAP 466, 467

Beaufuagter des Führers für Wirtschafisfragen 358

Beauftragter des Reichsverkehrsministeriums für das Schwarze Meer 372

Beauftragter des Reichsverkehrsministeriums für den „Seedienst OstpreuBen“ 372

Beauftragter des Reichsverteidigungskommissars im Wehrkreis XI 67

Beauftragter für alle Fragen der Technik und ihrer Organisation 459

Beauftragter für das Informationswesen im AA 48

Beauftragter für das Wohnungshilfswerk des Gaus Koblenz-Trier 483

Beauftragter für den Holzbau 363

Beauftragter für den motorisienen Transpon der Kriegswinschaft 359

Beauftragter für den Neubau des Reiches 459

Beaufuragter für den Totalen Krieg 362

Beauftragter fiur den Transpor der Kohle 359

Beaufuragter für den Vierjahresplan 272, 326 . 358-360, 413

Beauftragter für die Bewirtschaftung von Festkraftstoffen 363

Beaufuragter für die Förderung der Erdölgewinnung 359

Beauftragter für die Rohstofferfassung 359

Beaufuragter für die Verlagerung der Elektroindustrie 362

Beaufuragter für die Verwaltung der Reichsvermögenswerte im früheren Geschäftsbereich Speer 364

Beaufuragter für Fragen der Finanz- und Steverpolitik 459

Beauftragter für Italien 363

Beauftragter für Räumungsfragen im Gau Koblenz-Trier 483

Beauftragter für Trockeneis des Reichsbeauftragten für Chemie 378

Beauftragter für WeiBtorf 375

Befehlshaber der Ordnungspolizei

- Hannover 161

- Münster 33, 161

- Saarbrïcken 161

- Wiesbaden 161

Befehlshaber der Panzerschiffe bzw. Schlachtschiffe 236 
Befehlshaber der Sicherheitspolizei und des SD

- Baden-Elsab 133

- Metz 139

- Rhein-Westmark 139

Befehlshaber des Ersatzheeres 114, 434

Befehlsstelle Ostland der Reichsjugendfuihnung 498

Behörde des Senators für das Bildungswesen. Bremen 271

Behörde für Schiffahr, Handel und Gewerbe. Bremen 393

Behörde für Volkstum, Kirche und Kunst, Hamburg 308

Bekenntnissynode, kurhess. 88

Beratungsstelle der Vereinigung der Verleger für Volksliteratur 311

Berarungsstellen fuir Erb- und Rassenpflege 72, 240

Bereich West der Reichsstudentenführung 506

Bergakademie Clausthal 266

Berliner Philharmonisches Orchester 262. 338

Berliner Verkehrsgesellschaft (BEVAG) 102

Bernhard-Rust-Hochschule, Braunschweig 301, 307

Berufspädagogisches Institut Hamburg 25

BeschluBstelle in Rechtsangelegenheiten der Evangelischen Kirche 266

Besonderer Strafsenat des Reichsgerichts 198

Betriebskrankenkasse des Reichs $\mathbf{4 1 8}$

Beutestelle der Reichshauptkasse 327

Bevollmächtigter für den Nahverkehr Kassel 88

Bevollmächtigter für den Nahverkehr Westfalen 67

Bevollmächtigter für die Erzeugung von Mineralobl, Kautschuk und Leichtmetallen. von SchieB- und Sprengstoffen sowie die Erzeugung von chemischen Kampfmitteln 378

Bevollmächtigter für Hochfrequenzforschung 389

Bevollmächtigter für kernphysikalische Forschung 272

Bevollmächtigter General der deutschen Wehrmacht in Italien $\mathbf{4 4 0}$

Bevollmächtigter zum Reichsrat, braunschw. 53

Bezirkgeschäftsstelle Altona des NSRB 519

BezirksausschuB Osnabrück 247

BezirksausschuB Trier 100

Bezirksemährungsamt Trier 100

Bezirksgericht Bayern des Reichsvertandes der Deutschen Presse 311
Bezirksregienung

- Aachen 78, 156, 161, 443, 483

- Arnsberg 66, 79

- Aurich 81, 152, 458

- Birkenfeld 111

- Düsseldorf 66, 83, 144, 158

- Eutin 111

- für die Pfalz 9, 110

- für Mittelfranken 149, 150, 157, 163, 255

- fur Niederbayern-Oberpfalz 105, 458

- für Niederbayern 106

- für Oberbayern 104

- für Oberfranken und Mittelfranken 107. 493

- fir Oberfianken 108

- für Oberhessen 111

- fur Rheinhessen 111

- für Schwaben 109

- für Starkenburg 111

- für Unterfranken 109, 160

- Hannover 84

- Hildesheim 86

- Kassel 87

- Koblenz 88, 147

- Köln 66, 89

- Lüneburg 90

- Minden 92

- Münster 94

- Osnabrick 95, 458

- Schleswig 96, 458

- Sigmaringen 97

- Stade 98

- Trier 99

- Wiesbaden 101

Bezirksstelle Bremen der Reichsgruppe Industrie 381

Bezirksstelle Freiburg der Landesplanungsgemeinschaft Baden 352

Bezirksstelle Nordwestdeutschland der Reichsvereinigung der Juden 342

Bezirksstelle Unterweser/Unterelbe der Reichsgnuppe Industrie 381

Bezirksverbände Kassel und Nassau 103

Bezirksvertand Pfalz 110

Bezirksverwaltungsgericht

- Aachen 246

- Arnsberg 246

- Aurich 246

- Berlin 247

- Düsseldorf 247

- Hannover 247

- Lüneburg 247

- Minden 247

- Osnabrïck 247

- Schleswig 247

- Sigmaringen 248

- Stade 248 
Binnenschiffahrtsabteilung des Reichsverkehrsministeriums 370

Biologische Reichsanstalt für Land- und Forstwirtschaft 385

Bischöfliches Ordinariat Münster 270

Blohm und Voss, Werf 437

Bochumer Verein fü Bergbau und GuBstahlfabrikation A.G. 133

Börsenverein des deutschen Buchhandels 311

Robert Bosch-Stiftung 303

Botschaften Ankara, Brüssel, London, Madrid. Moskau, Nanking, Paris, Peking, Rom (Quirinal und Vatikan), Tokio, Warschau und Wien 50, 51

Brandenburgisch-PreuBisches Hausarchiv 337

Buderus'sche Eisenwerke, Wetzlar 88, 251

Büro Berlin des Reichssparkommissars 335

Bund der Saarvereine 282

Bund der Schweizer in Grobdeutschland 486 , 490

Bund Deutscher Architekten 314

Bund Deutscher Mädel s. BDM und HJ

Bund Deutscher Osten 178, 304

Bund Deutscher Westen 36

Bund für deutsche Kirchen 88

Bund Großdeutscher Jugend 498

Bund Oberland 84, 474

Bund Reichsdeutscher Buchhändler 314

Bund zur Pflege persönlicher Freundschaften mit Ausländern e. V. 262

Bundesamt für das Heimatwesen 4, 247

Cautio-Treuhand GmbH 262, 465

Charité, Berlin 266

Chef der Bandenkampfvertände 135

Chef der Heeresleitung 433

Chef der Heeresrüstung und Befehishaber des Ersatzheeres 434

Chef der Ordnungspolizei 162

Chef der Sicherheitspolizei und des SD 38 , 121

Chef der Zivilverwaltung

- im ElsaB 55, 268, 331, 332, 336

- in Kärnten und Krain 339

- in Lothringen 9, 55

- in Luxemburg 55

- in Untersteiermark 339

Chef des Ausbildungswesens (Chef AW) der SA 492

Chef des Fernmeldewesens der SS 119

Chef des Kriegsgefangenenwesens im OKW 431

Chefs des Transport-. Kriegskarten- und Vermessungs- und Heeresnachrichtenwesens im OKH 43

Chemisch-Technische Reichsanstalt 274

Chiledeutsche Kameradschafi 173
Christian-Albrechts-Universitäl s. Universität Kiel

Christlicher Metallabeiterverband 244

Daimier-Benz A.G. 437

Danlispendenstifturig des deuischen Volkes 5

Deputation für Handel, Schiffahr! und Gewerbe, Hamburg 392

Deutsch-Hannoversche Partei 90

Deutsch-italienische Gesellschaft 286, 487

Deutsch-japanische Gesellschaft 49,503

Deutsch-niederiändische Gesellschaft 34, 47 . 79

Deutsch-spanische Gesellschaft 49

Deutsch-südafrikanische Gesellschaft 456

Deutsch-völkische Freiheitsbewegung 145

Deutsch-Westafrikanische Handelsgeselischafi 43

Deutsche Akademie 14, 294, 295, 306, 314

Deutsche Akademie für Bauforschung 410

Deutsche Akademie für Lufufahrtforschung 438

Deutsche Akademie für Städtebau, Reichsund Landesplanung 348

Deutsche Akademie für Wohnungswesen 334, 410

Deutsche Akademie in Prag 306

Deutsche Aubeiter Partei (DAP) 473

Deutsche Arbeitsfront (DAF) 2, 14, 44, 54 $58,73,76,79,80,83,84,86,87,89$, $158,244,250,251,296,409,447,449$. $460,484,486,488,489,508-515$

Deutsche Archivkommission für Estland und Lettland 178

Deutsche Auslandsrundfunkgesellschaft Interradio A.G. 48,317

Deutsche Ausnüstungswerke GmbH 121

Deutsche Bodenkultur A.G. 37

Deutsche Briefkastenreklame 121

Deutsche Bruckner-Gesellschaft 263

Deutsche Bücherei, Leipzig 262, 311

Deutsche Burse

- Marburg 293

- München 295

- Münster 296

- Stuttgar 303

Deutsche Demokratische Partei 473

Deutsche Edelmóbel A. G. 121

Deutsche Erd- und Steinwerke 121

Deutsche Filmherstellungs- und Verwertungsgesellschaft (DFG) 464

Deutsche Forschungsanstalt fur Lebensmittelchemie 295

Deutsche Forschungsanstalt für Psychiatrie 295

Deutsche Forschungsanstalt für Segelflug .Ernst Udet", Ainring 439 
Deutsche Forschungsgemeinschaft 272, 288

Deutsche Freiheitspartei 123, 150

Deutsche Geschäftsstelle der Internationalen Stomkommissionen 371

Deutsche Gesellschaft für Gefängniskunde 186

Deutsche Gesellschafi für öffentliche Arbeiten 335

Deutsche Gesellschaft für Rassenhygiene 294

Deutsche Gesellschaft für Wohnungswesen 410

Deutsche Glaubensbewegung 3, 8, 159, 269 , 299

Deutsche Golddiskontbank (Dego) 346

Deutsche Heeresmission in Rumänien $\mathbf{4 4 0}$

Deutsche Heilmituel GmbH 121

Deutsche Heimgestaltung GmbH 121

Deutsche Heimschulen Blaubeuren und Maulbronn 278

Deutsche Historische Institute Paris und Rom 274

Deutsche Hochschule für Politik 5, 275, 280

Deutsche Industriekommission in der Schweiz 440

Deutsche Kolonialgesellschaft 469

Deutsche KongreBzentrale 262

Deutsche Lufthansa 326

Deutsche Meisterwerkstätten GmbH 121

Deutsche Reichsbahn 326, 369, 370, 372, $387,388,402,403$

Deursche Reichslouerie 327

Deutsche Rentenbank-Kreditanstalt 327

Deutsche Revisions- und Treuhand A.G. 188, 375

Deutsche Schieferöl GmbH 121

Deutsche Schillerstifung 262, 311

Deutsche Siedlungsbank 384

Deutsche Sparkassenschule Hannover 85

Deutsche Stifung 178

Deutsche Studentenschafi 305, 503, 504, 507, 508

Deutsche Torfverwertung GmbH 121

Deutsche Umsiedlungs-Treuhand-Gesellschaft 175

Deutsche Universität Prag 282

Deutsche Versuchsanstalt für Ernährung und Verpflegung 121

Deutsche Versuchsanstalt für Luftuahr 438

Deutsche Volkspartei (DVP) 4, 275

Deutsche Wirtschaftsbetriebe GmbH 121

Deutsche Wirtschaftsdienst GmbH 381

Deutsche Wissenschaftliche Institute Belgrad, Budapest, Kopenhagen, Madrid, Sofia 314

Deutsche wissenschaftliche Kommission für Meeresforschung 384

Deutsche Zentralgenossenschaftskasse 326

Deutscher Abstinentenbund 59
Deutscher Ärategerichtshof, München 257

Deutscher Akademischer Austauschdienst 281, 305, 505

Deutscher Bevollmächtigter General in Kroatien $\mathbf{4 4 0}$

Deutscher BilderdiensuVölkischer Kunstverlag 121

Deutscher Bühnenverein 268, 320

Deutscher Chorsängerverband 320

Deutscher DampfikesselausschuB 375

Deutscher Eisenbahnverkehrsvertand 372

Deutscher Frauenarbeitsdienst 420, 421, 422, 423, 424, 425. 502

Deutscher Gemeindetag 24, 35, 37, 60,63, $74,75,470$

-, Landes- und Provinzialdienststellen 75

Deutscher General beim Oberkommando der rumänischen Wehrmacht $\mathbf{4 4 0}$

Deutscher Industrie- und Handelstag 379

Deutscher Kolonialfunk 48

Deutscher Kriegertund 474

Deutscher Lehrerverein 521

Deutscher Lichtbilddienst 262

Deutscher Metallarbeitervertand 244

Deutscher Ring, Versicherungsgesellschaft 511

Deutscher Seefischerei-Verein 386

Deutscher Siedlertund 508, 512

Deutscher Tanzerbund 320

Deutscher Tierärategerichtshof 257

Deutscher Verein fur offentliche und private Fürsorge 25

Deutscher Verlag für Politik und Wirschaft 262

Deutscher Zeitungswissenschaftlicher Verband 292

Deutsches Ausland-Institut 70, 176, 339, 472

Deutsches Auslandswissenschafuliches Institut 275

Deutsches Frauenwerk 120, 501, 508

Deutsches Instiut fuir auBenpolitische Forschung 47

Deutsches Institut für Jugendhilfe e. V. 63

Deutsches Institut für Wirtschafisforschung 431

Deutsches Instiut Paris 36

Deutsches Jungvolk 497; s. auch H

Deutsches Ledermuseum Offenbach 338

Deutsches Nachrichtenbuiro (DNB) 47, 48, 262, 318

Deutsches Oberlandesgericht Prag 199

Deutsches Opernhaus Berlin 320, 338

Deutsches Propaganda-Acelier 262

Deutsches Rotes Kreuz 61, 73, 165, 167. 430

Deutsches Schauspielhaus Hamburg 23

Deutsches Sprach-Archiv 27I 
Deutsches Staatsministerium für Böhmen und Mähren 55

Deutsches Studentenwerk 289, 302

Deutsches Tanz- und Unterhaltungsorchester 262

Deutsches Theater Berlin 338

Deutsches Theater Wiesbaden 321

Deutsches Volksbildungswerk 76, 467, 486. 488

Deutsches Wohnungshilfswerk $31,85,352$. 458, 483

Deutsches Zentralinstitut für Erziehung und Unterricht 276

Deutschlandsender 316

Deutschnationale Volkspartei (DNVP) 4

Deutschnationaler Handlungsgehilfenverband 244, 421

Devisenfahndungsamt 125

Devisenstelle

- Braunschweig 343

- Düsseldorf 357

- Frankfurt 343

- Hamburg 342, 357

- Hannover 357

- Kassel 343

- München 357

- Münster 357

Dienststelle Bukarest des Reichskommissars für die Seeschiffahr 372

Dienststelle des Beauftragten für auBenpolitische Fragen (Ribbentrop) 457, 459

Dienststelle für Feindvermögensverwaltung beim Generalkommissar für Finanz und Wirtschaft des Reichskommissars für die Niederlande 188

Dienststelle Kinderlandverschickung der Reichsjugendfuhrung 499

Dienststelle SS-Obergruppenführer HeiBmeyer und Inspekteur der Heimschulen $117,278,279$

Dienststelle Wien der Rechtsabteilung des AA 46

Dienststrafhof Stuttgan 255

Dienststrafkammer

- Aurich 255

- Berin 255

- Hamburg 256

- Hannover 256

- Oldenburg 256

- Schleswig 256

- Sigmaringen 256

Dienststrafsenal beim Reichsgericht 254

Dienststrafsenate Karlsruhe und München 255

Dillinger Hüttenwerke 188

DisziplinarausschuB der Universität München 295
Disziplinargericht der Obersten SA-Führung 492

Disziplinargericht der Universität Freiburg 284

Disziplinargericht der Universität Heidelberg 288

Disziplinarhof Bremen 255

Disziplinarhof für lübeckische Beamte 256

Disziplinarhof Hamburg 255

Disziplinarkammer

- Ansbach 255

- Bremen 255

- Bückeburg 208

Dolmetscher-Institut Heidelberg 289

Domkapitel Padertorn 93

Dornier-Fugzeugwerke 437

Dozentenakademie

- Kiel 290

- Rittmarshausen 286

- Tübingen 298

Dr. Goebbelsstiftung für Bühnenschaffende (für Kulturschaffende) 310

Drahtloser Dienst 316

Dunlop Rubber Company 187

Eberhard-Karłs-Universität s. Universität Tübingen

Effekten-Giro-Depot Berlin-Wien 347

Eher Verlag. Zentralverlag der NSDAP 465. 466

Ehren- und Disziplinargericht der DAF

- Berlin 479

- Bielefeld-Haile 515

- Hessen-Nassau 514

- Koblenz-Trier 514

- Württemberg-Hohenzollern 515

Ehrengericht des Reichsnährstands 257

Ehrengericht, ärztiches. Berlin 102

Ehrengerichtshof beim Deutschen Handwerks- und Gewerbekammertag 257

Ehrengerichtshof der gewerblichen Wirtschaft 380

Ehrengerichtshof für die deutschen Rechtsanwälte, Leipzig 257

Eierwirtschaftsverband Hannover 398

Eierwirschaftsvertand Hessen-Nassau 399

Eigenkanzlei Darté 469

Eildienst fur private und amtliche Handelsnachrichten 318

Einsatzgruppen Deutschland V. VI, Hansa und Rhein-Ruhr der OT 364

Einsatzstab Litzmannstadt 175

Einsatzstab Reichsleiter Rosenberg 466

Einwandererzentralstelle Litzmannstadt 174. 175

Eisenbahnabteilungen des Reichsverkehrsministeriums 369 
Elektrizitätswerk Wesertal 20

Entschädigungsgericht 243

Entschuldungsämter Frankfur und Wiesbaden 395

Erbbiologische Landeszentrale, braunschw. 172

Erbgesundheitsgericht

- Amsberg 240

- Augsburg 240

- Berlin 240

- Bielefeld 240, 241

- Braunschweig 240

- Bremen 240, 241

- Bückeburg 208

- Deggendorf 241

- Dortmund 241

- Flensburg 241

- Freiburg 241

- Gieben 241

- Hagen 241

- Hanau 241

- Hannover 241

- Kempten 241

- Kiel 241

- Konstanz 241

- Landshut 241

- Limburg 241

- Lörrach 241

- Lübeck 241

- Marburg 241

- Memmingen 241

- München 241

- Offenbach 241

- Osnabrück 241

- Passau 241

- Saarbrücken 241

- Schweinfurt 241

- Traunstein 241

- Trier 241

- Verden 241

- Waldshut 241

- Wiesbaden 241

- Wuppertal 242

Erbgesundheitsobergericht

- Berdin 184

- Celle 184

- Frankfurt/Main 184

- Hamburg 240

- Hannover 184

- Karisrihe 240

- Kassel 184

- Kiel 184

- Köln 240

Erbhofgericht

- Bamberg 240

- Darmstadt 239

- Hamburg 240
Erbhofgericht (Forts.)

- Karisruhe 240

- München 240

Erfassungs- und Ergänzungsamt der SS 117

Eholungsheime für naturgemäße Heil- und Lebensweise e. V. 121

Erneuerungsstock für Land- und Forstwirtschaft. hess. 18

Erzbischöflicher Stuhl Köln 281

Erziehungs- und Ausbildungsamt des RAD 420

Erziehungsheime Homberg/Efze, Karishof (in Wabern) und Lahneck (in Buchenau) 103

Europäischer Jugendverband 498

Europäischer Revolutionssender 317

Evangelischer Marinestationspfarrer (Marinedekan) Wilhelmshaven 453

Evangelisches Lehrerseminar Esslingen 307

Externsteine-Stifung 116

Fachgruppe Bauwesen des NS-Bundes Deutscher Technik 523

Fachgruppe Handelsvertreter und Handelsmakler 380, 382

Fachgruppe Kraffahrzeuge, Kraftstoffe, Garagen 380

Fachgruppe Nebenbahnähnliche Kleinbahnen und Private Bahnen des allgemeinen Verkehrs 388

Fachgruppe Reichsmusikerschafi der Reichsmusikkammer 310

Fachschaft Bühne der Reichstheaterkammer 310,320

Fachschaft der katholisch-kirchlichen Presse der Reichspressekammer 310

Fachschaft Hochschulen im NSLB 507

Fachschaft inländischer Filmvertrieb der Reichsfilmkammer 312

Fachschaft Kultur- und Werbefilm der Reichsfilmkammer 312

Fachschaft Leihbücherei der Reichsschrifttumskammer 314

Fachschaft Musikerziehung der Reichsmusikkammer 313

Fachschaft Verlag der Reichsschriftumskammer 311

Fachschaft VII. Reichsverband der Deutschen Presse, der Reichspressekammer 311

Fachschaften Film, FilmauBenhandel, -bearbeitung und -herstellung der Reichsfilmkammer 312

Fachverband Rundfunkpresse der Reichspressekammer 318

Fahndungsabteilung des Zentralgerichts des Heeres 235

Fakultätentag, ev.-theolog. 289, 293, 298

Fakultätentag, medizinischer 292 
Feldbischof, evangelischer und katholischer 432

Feldeisenbahnkommandos 370

Feldgericht des Befehlshabers des Luftgaues VIII. AuBenstelle Breslau 234

Feldgericht des Kommandeurs der 4. Flakdivision 236

Feidgericht des Kommandierenden Generals und Befehlshabers im Lufigau VI.

AuBenstelle Düsseldorf 236

Feldkommandostelle Reichsführer SS 114

Feldwirtschaftsamt im OKW 43 !

Feldzeugkommando VII 445

Festspielhaus Bayreuth 268

Festungsdienststellen Trier, Düren, Karlsruhe, Helgoland. Traben-Trarbach und Pirmasens 449

Festungspionierstäbe Nr. 10 und 14449

Fieseier-Flugzeugwerke. Kassel 88.437

Filmoberprifstelle 308

Fumprïfstellen Berlin und München 308

Filmstelle des Reichsverkehrsministeriums 372

Finanzakademie 327

Finanzausgleichsaint 62

Finanzdeputation IV. Hamburg 341

Finanzgericht Hannover 249

Finanzgericht München 250

Finanzministerium, bad. 331

Finanzministerium, bayer. 330

Finanzministerium, braunschw. 334, 392

Finanzministerium, oldenburg. 333

Finanzministerium, preuB. 328

Finanzministerium, württemberg. 331

Finanzsenator Bremen 335

Flämischer Arbeitskreis 78

Flakdivisionen, 1., 4., 5., 7., 8., 21. und 26. 452

Fakdivisionen, 3., 4. 236

Flakdivisionen, 21., 26. 237

Flakregimenter Nr. 5, 12, 14, 16, 24, 25 , $26.29,46,47,49,51,54,60,66.75,93$. 122, 139, 155 und 179452

Fliegendes Standgericht im Wehrkreis III 237

Fliegendes Standgericht West 237

Fliegerhorst Lippstadt 450

Flugabwehrkommando Schwarzwald 452

Focke-Wulf-Flugzeugwerke 363. 437

Forschungsamt des Reichsluftfahrtministeriums 317,438

Forschungsanstalt der Deutschen Reichspost 389

Forschungsanstalt für das deutsche Buchwesen 121

Forschungsbeirat Vermessungstechnik 66

Forschungsgemeinschaft Weser-Ems 270
Forschungsgesellschaft für deutsches Straßenwesen 372

Forschungsstätte für Karst- und Höhienkunde 116

Forschungsstelle. .Deutscher Bauernhof' 30

Forschungsstelle .. Weltanschauliche und praktische Lebensgestaltung" 467

Forschungsstelle ..Westfalen in aller Welt". Münster 177

Forschungsstelle für deutschen Sozialismus 291

Forschungsstelle für internationale Gewerkschaftsfragen $5 ! 1$

Forschungsstelle für Kolonialwirtschaft, staatliche. Bremen 393

Forschungsstelle für Meeresforschung Norderney 82

Forschungsstelle für niedersächsische Bauerngeschlechter 399

Forschungsstelle für Wehrwirtschaft 283. 358, 431

Forschungsstelle Rasse und Raum OstHannover 99

Forschungsstelle Rheinland, Düsseldorf 177

Forschungsstelle RuBlanddeutschtum 176

Forschungswerk ..Wald und Baum" 116

Forst- und Jagdministerium, braunschw. 392

Forstabteilung der Landesbauernschaft Bayern 399

Forsthochschule Eberswalde 266, 368

Forstliche Hochschule Hannoversch Münden 286, 295, 368, 368; s. auch Hermann-

Göring-Akademie

Fotografisches Bildarchiv führender Nationalsozialisten 268

Franz-Seldte-Institut Magdeburg 410

Franziskanerbrüder 37

Frauenschule „Haus der Frau“, Bad Oeynhausen 502

Frauenwirtschaftskammer Hamburg 397

Frauenzuchthaus Aichach 190

Frauenzuchthaus Anrath 190

Freie Gewerkschaften 123

Freikorps .Adolf Hitler" 1945486

Freimaurerloge Hamm/Westf. 143

Freiwilliger Arbeitsdienst (FAD) 8, 20, 22 $25,37,54,72,79,82,84,85,89,90$, $410,411,414,419,421,422,424,425$

Freunde der Aachener Hochschule 300

Freunde der Burg Rothenfels 152

Freundeskreis Himmler 115

Friedrich-Alexander-Universität s. Universität Erlangen

Friedrich-Wilhelm-Universität s. Universität Berlin

Frobenius-Institut (für Kulturmorphologie) 283 
Führer der Landespolizei Lippe 20

Führer der U-Boote-Ausbildungsflottillen 236

Führerbegleitkommando 127

Führerhauptquartier 38, 139, 428

Führermuseum Linz 459

Führerschule der Sicherheitspolizei 125

Führerschule des motorisierten Feldjägerkorps 496

Führerschulungslager Herdorf (Sieg) des RAD 423

Führungsamt der SS 117

Fürungshauptamt det SS 118, 119

Fühungsstab Politik des Reichsministeriums für die besetzten Ostgebiete 55

Führungsstab Wirtschaft im Wehrwirtschaftsbezirk XIII 484

Fürsorgeoffiziere Lüneburg und Stade 448

Gartenbauwirtschaftsstelle Westfalen 398

Gartenbauwirtschaftsverband Hannover 398

Gauamt "Schonheit der Arteit" WestfalenSüd der DAF 80

Gauamt Ausbildungswesen WürtumbergHohenzollem 491

Gauamt fir Agrarpolitik Westfalen-Nord 489

Gawamt für Beamte Würtemberg-

Hohenzollern 520

Gauamt für das Landvolk Baden 477

Gauamt für Kommunalpolitik

- Baden 113, 477

- Bayerische Ostmark 105

- Disseldorf 480

- Hamburg 482

- Koblenz-Trier 483

- Würtemberg-Hohenzollern 491

Gauamt für Rassenpolitik

- Baden 477, 478

- Franken 481

- Köln-Aachen 177, 483

- München-Oberbayern 485

- Süd-Hannover-Braunschweig 488

- Württemberg-Hohenzollern 491

Gauamt für Technik Essen 76

Gauamt für Technik WürttembergHohenzollern 491

Gauamt fir Volksgesundheit WürtembergHohenzollern 98, 490

Gauamt für Volkstumsfragen

- Bayerische Ostmark 478

- Köln-Aachen 483

- Westfalen-Nord 488

Gauamt für Volkswohlfahr WürtuembergHohenzollern 77

Gauarteitsamt

- Bayreuth 413

- Berlin 413

- Disseldorf 413
Gauarbeitsamt (Forts.)

- Franken 412

- Hamburg 413

- Köln-Aachen 413

- Kurhessen 413

- Mainfranken 412

- Oberbayern 412

- Rhein-Main 413

- Schleswig-Holstein 413

- Schwaben 412

- Süd-Hannover-Braunschweig 413

- Weser-Ems 412

Gauarbeitsgemeinschaft. Das schöne Dorf" Süd-Hannover-Braunschweig der DAF 76

Gauarbeitsgemeinschafi für Volkstumspflege und Heimatschutz Weser-Ems 270

Gauarbeitsgemeinschaft Vorgeschichte Westfalen-Nord 34

Gauarbeitskammer Westfalen-Nord 67

Gawarchiv

- Baden 477

- Franken 481

- Hessen-Nassau 482

- Mainfranken 484

- OstpreuBen 475

- Saarpfalz 486

- Süd-Hannover-Braunschweig 487

- Westfalen-Nord 488

- Würtemberg-Hohenzollern 491

Gaubeauftragter Württemberg-Hohenzollern des Reichssportführers 71

Gaubetriebsgemeinschaften Bau und Steine und Erden der DAF München-Oberbayern 514

Gaufachschaft Reichssteuerverwaltung Hamburg im Reichsbund der Deutschen Beamten 520

Gaufachschaft Volkspflegerinnen WestfalenNord der DAF 515

Gaufravenschaftsleitung

- Mainfranken 502

- Schwaben 502

- Westfalen-Nord 502

- Würtemberg-Hohenzollern 502

Gaufrauenschaftsschule Westfalen-Nord Haus Botzlar, Selm-Beifang 502

Gauführerschule Hamburg der NSDAP 341

Gauführerschule Hessen-Nassau der NSDAP. Kronberg im Taunus 482

Gaugericht der NSDAP

- Baden 477

- Bayerische Ostmark 478

- Essen 480

- Koblenz-Trier 483

- Köln-Aachen 483

- Mainfranken 160, 484

- Schwaben 487 
Gaugericht der NSDAP (Fons.)

- Westfalen-Nord 488

- Westmark 486

- Würtemberg-Hohenzollern 491

Gaugeschäftsstellen Baden und Bayreuth des NS-Deutschen Ärztebundes 518

Gauheimatwerk Süd-Hannover-Braunschweig 73, 270,286

Gauheimstättenamı WürttembergHohenzollern 70. 515

Gauheimstätlenwerk München-Oberbayern 514

Gauinspektion Würtuemberg-Hohenzollern II 491

Gauinspektionen Westfalen-Nord 489

Gaujägermeister Süd-Hannover-Braunschweig 85

Gaukulturamt

- Schwaben 487

- Westfalen-Nord 34. 488

- Westfalen-Süd 34

Gaukulturfachberaterin Westfalen-Nord, Bielefeld 489

Gaukulturrat Süd-Hannover-Braunschweig 286

Gaukulturwerk Weser-Ems der NSDAP 103

Gauleitung

- Baden(-ElsaB) 477

- Bayerische Ostmark (ab 1943 Bayreuth) 157, 478

- Berlin 479

- Düsseldorf 479

- Essen 480

- Franken 480

- Hamburg 24, 482

- Hessen-Nassau 482

- Koblenz-Trier (Moselland) 483

- Köln-Aachen 483

- Kurhessen 484

- Mainfranken 14, 160, 484

- München-Oberbayern 476. 485

- Ost-Hannover 486

- Saarpfalz (Westmark) 10. 486

- Schleswig-Holstein 486

- Schwaben 486

- Süd-Hannover-Braunschweig 85, 487

- Weser-Ems 18, 488

- Westfalen-Nord 35, 488

- Westfalen-Süd 35, 81, 415, 489

- Württemberg-Hohenzollern 490. 522

Gauorganisationsamt

- Baden 477, 478

- Bayerische Ostmark 478

- Hamburg 460

- Hessen-Nassau 482

- Mainfranken 484

- München-Oberbayern 485
Gauorganisationsamt (Forts.)

- Saapfalz 486

- Schwaben 487

- Weser-Ems 488

- Wüntemberg-Hohenzollern 460.490

Gaupersonalamt

- Baden 477, 478

- Bayerische Ostmark 478

- Franken 481

- Mainfranken 484

- München-Oberbayern 485

- Würtemberg-Hohenzollern 490

Gaupresseam!

- Mainfranken 484

- Schwaben 487

- Würtlemberg-Hohenzollern 490

Gaupropagandaamt, -leitung

- Baden 477, 478

- Bayerische Ostmark 478

- Berlin 479

- Düsseldorf 479

- Hamburg 482

- Hessen-Nassau 482

- Koblenz-Trier 483

- Köln-Aachen 483

- Mainfranken 463, 484

- München-Oberbayern 485

- Saarpfalz 486

- Schwaben 487

- Süd-Hannover-Braunschweig 487

- Weser-Ems 488

- Wüntemberg-Hohenzollern 463, 490

Gauquarieramt Süd-Hannover-Braunschweig 31

Gaurechisamt

- Baden 477

- Hessen-Nassau 482

- München-Oberbayern 519

Gaurechtsberatungsstelle Bayreuth der DAF 513

Gauring für Volksaufklärung und Propaganda

- Baden 478

- Franken 481

- München-Oberbayern 485

Gauschatzmeisteramt

- Baden 477. 478

- Düsseldorf 479

- Franken 481

- Hessen-Nassau 482

- Koblenz-Trier 483

- Kurhessen 484

- Mainfranken 484

- Schwaben 487

- Westfalen-Nord 488

- Würtiemberg-Hohenzollern 490

Gauschule des Gaus Berlin. TardorfHuberiushöhe 479 
Gauschule des Gaus Köln-Aachen. Honnef 483

Gauschule des Gaus Kurhessen ..Karl Weinrich", Bad Sooden-Allendorf 484

Gauschule des Gaus München-Oberbayern. Niedernfels 485

Gauschule des Gaus Weser-Ems. Bad Essen 95

Gauschule des NSLB Bayerische Ostmark. Burg Hohenberg 522

Gauschule des NSLB Moselland ..Hans Schemm", Schlob Friedewald 522

Gauschulungsamt

- Baden 477, 478

- Bayerische Ostmark 478

- Berlin 479

- Franken 481

- Köln-Aachen 483

- Mainfranken 484

- Schwaben 487

- Westfalen-Nord 488

- Württemberg-Hohenzollern 491

Gauschulungsburg des Gaus Baden, Frauenalb 477

Gauschulungsburg des Gaus Franken. Schwarzenberg 481

Gauschulungsburg des Gaus Schwaben, Bachhagel/Krs. Dillingen 487

Gauschulungslager des NSDStB Rittmarshau$\operatorname{sen} 506$

Gausippenamt

- Baden 331

- Hessen-Nassau 75

- Westfalen-Nord 213

Gaustabsamt

- Baden 478

- Franken 481

- Hessen-Nassau 482

- Koblenz-Trier 483

Gaustelle für Volkstumsfragen und Auswandererforschung Süd-HannoverBraunschweig 85

Gaustudentenführung

- Baden 505

- Bayreuth 505

- Hamburg 505

- Hessen-Nassau 505

- Köln-Aachen 293, 505, 507

Gauwaltung „Kraft durch Freude“ Düsseldorf der DAF 84

Gauwaltung Ausland des NSLB 521

Gauwaltung Baden der NSKOV 518

Gauwaltung Baden der NSV 516

Gauwaltung Baden des NSLB 522

Gauwaltung Baden-ElsaB der DAF 514

Gauwaltung Baden-ElsaB des NSRB 519
Gauwaltung Bayerische Ostmark (Bayreuth) der DAF 513. 515

Gauwaltung Bayerische Ostmark des NSLB 520. 522

Gauwaltung Bayreuth der NSV 517

Gauwaltung Essen der DAF 515

Gauwaltung Essen des NSLB 520

Gauwaltung Franken der DAF 515

Gauwaltung Franken des NSLB 520

Gauwaltung Hamburg der DAF 514

Gauwaltung Hamburg des NSLB 520

Gauwal tung Hessen-Nassau der DAF 514. 515

Gauwaltung Hessen-Nassau des NSLB 522

Gauwaltung Koblenz-Trier der DAF 484. 514

Gauwaltung Koblenz-Trier der NSV 484

Gauwaltung Köln-Aachen der DAF 515

Gauwaltung Köln-Aachen der NSKOV 518

Gauwaltung Kurhessen der NSV 517

Gauwaltung Kurhessen des NSLB 520

Gauwaltung Mainfranken der DAF 515

Gauwaltung Mainfranken der NSV 517

Gauwaltung Moselland der DAF 515

Gauwaltung München-Oberbayern der DAF 514

Gauwaltung München-Oberbayern der NSKOV 518

Gauwaltung München-Oberbayern des NSLB 522

Gauwaltung München-Oberbayern des NSRB 519

Gauwaltung Saarpfalz/Westmark der DAF 515

Gauwaltung Schlesien der DAF 510

Gauwaltung Schwaben der DAF 514

Gauwaltung Schwaben der NSV 517

Gauwaltung Schwaben des NS-Bundes Deutscher Technik 523

Gauwaltung Sïd-Hannover-Braunschweig der DAF 515

Gauwaltung Weser-Ems der DAF 515

Gauwaltung Weser-Ems des NSLB 522

Gauwaltung Westfalen-Nord der DAF 515

Gauwaltung Westfalen-Nord der NSKOV 518

Gauwaltung Westfalen-Nord der NSV 517

Gauwaltung Westfalen-Süd des NSRB 519

Gauwaltung Wüntemberg-Hohenzoliern der DAF 515

Gauwaltung Wüntemberg-Hohenzollern der NSKOV 518

Gauwaltung Wüntemberg-Hohenzollern der NSV 517

Gauwaltung Würtemberg-Hohenzollern des NSLB 522 
Gauwaltung Württemberg-Hohenzollern des NSRB 519

Gauwirtschaftsberater

- Baden 477, 478

- Bayerische Ostmark 478

- Franken 481

- Hessen-Nassau 482

- Mainfranken 484

- Westfalen-Süd 490

- Wïruemberg-Hohenzollern 491

Gauwirschafiskammer

- Baden bzw. Oberrhein 396

- Bayerische Ostmark 396, 478

- Düsseldorf 396

- Essen 397

- Hamburg 397

- Hessen-Nassau 482

- Köln-Aachen 397

- Schwaben 397

- Weser-Ems 72, 95, 397

- Westfalen-Nord 396

- Westfalen-Süd 396

- Westmark 397

Gauwohnungs- und Siedlungsamt Baden 333

Gauwohnungskommissar

- Berlin 102

- Ost-Hannover 91

- Weser-Ems 334

Gebietsbeaufuragter für die Regelung der Bauwirtschaft in Schleswig-Holstein 352 Gebietsführerschule .Wilhelm Neth". Stutigar-Solitude 501

Gebietsführerschule Bayerische Ostmark 478 Gebietsfuihrung der $\mathrm{H}$

- Baden (21) 499

- Bayerische Ostmark (22) 478

- Düsseldorf (34) 499

- Franken 500

- Hessen-Nassau (13) 500

- Hochland 499

- Köln-Aachen (11) 500

- Kurhessen (14) 500

- Mainfranken (39) 500

- Niedersachsen (8) 500

- Nordmark 499

- Ruhr-Niederthein 499

- Saar-Pfalz (25) 500

- Saapfalz 498

- Schwaben (36) 500

- Westfalen (9) 499, 501

- Württemberg (20) 499. 501

Gebirgsdivision, 1. 449

Geheime Feldpolizei. Gruppe 570442

Geheimes Staatsarchiv, preuB. 337

Geheimes Staatspolizeiamt (Gestapa) 121. $125,142,353,474$

Geheimes Staatspolizeiamt, bad. 139
Geheimes Staatspolizeiamt, hess. 139

Geheimes Staatspolizeiamt, preuBisches 138

Geheimes Staatspolizeiamt, würtemberg. 139

Gemeindeversorgungskasse, thein. 36

Gemeinschaft Asbest 384

Gemeinschaft Schuhe 384

Gemeinschaft Studentischer Vertände 5. 503

Gemeinschaftslager für Vermessungsbeamte 71

Gerneinschaftslager Hanns Kertl 188

Gemeinschafiswerk der DAF 511

Gendarmeriehauptmannschaft Wiesbaden 16 ?

Gendarmerieschulen Bad Ems und Freiburg 135

General Motors Corp. 187

Generalbauinspektor für die Reichshauptstadt 349

Generalbaurat der Hauptstadt der Bewegung 351

Generalbaureferent der DAF 511

Generalbetriebsleitungen Ost. Süd und West der Reichsbahn $\mathbf{4 0 2}$

Generalbevolimächtigter für das Kraftfahrwesen 360

Generalbevoltmächtigter für den Arbeitseinsatz. 22, 336, 407, 408

Generalbevollmächtigter fur die Energiewinschaft 360

Generalbevollmächtigter für die Regelung der Bauwirtschaft 31, 349, 352, 359. 362

Generalbevollmächtigter für die Reichsverwaltung 58

Generalbevollmächtigter für die Wirtschaft in Serbien 359

Generalbevolimächtigter für Rüstungsaufgaben 359

Generalbevollmächtigter für Sonderfragen der chemischen Industrie 359

Generalbevollmächtigter für technische Nachrichtenmituel 359

Generaldirektion der Staatseisenbahnen. würt temberg. 402

Generalinspekteur der Grenzpolizei 125

Generalinspekteur der Panzertruppen 435

Generalinspekteur für den Zollgrenzschutz 328

Generalinspektor für das deutsche Strabenwesen 28, 362, 363, 372

Generalinspektor für Wasser und Energie $360,362,391$

Generalintendanz der preu8ischen Staatstheater 319

Generalintendanz der württembergischen Staatstheater 320

Generalkommando der Grenztruppen Saarpfalz 445 
Generalkonsulate Amsterdam. Barcelona. Charkow. Danzig. Innsbruck. Istanbul. Kattowitz, Posen. Thorn, Tiflis, Triest und Zürich 53

Generalluftzeugmeisteramt im OKL 437

Generalnachrichtenführer im OKL 437

Generalquartiermeister im OKH 435

Generalquartiermeister im OKL 437

Generalrat der deutschen Wirtschaft 3.15

Generalrat des Vierjahresplans 358

Generalsachverständiger für deutsche Rohund Werkstoffe 358

Generalstab der Luftwaffe 437

Generalstab des Heeres 433

Generaltreuhänder für die Sicherung deutschen Kulturgutes in den eingegliederten Ostgebieten 116

Generalverkehrsdirektion Osten. Warschau 402

Generalvertretung der Reichsbahn für Rumänien $\mathbf{4 0 2}$

Genossenschaft Deutscher Bühnenangehöriger 320

Geologische Landesanstalt Baden 332

Georg-August-Universitäı s. Universität Götringen

Gericht der 3. Flakdivision 236

Gericht der 21. Flakdivision 237

Gericht der 26. Flakdivision 237

Gericht der 5. Sicherungsdivision 236

Gericht der 6. Infanterie-Division 235

Gericht der 465. Infanterie-Division. Ludwigsburg 233

Gericht der Aufklärungsstreitkräfte 236

Gericht der Kriegsmarine Beriin 236

Gericht der Standort-Kommandantur Ingolstadt 236

Gericht des Admirals der Kampfverbände 236

Gericht des Admirals der Kriegsmarinedienststelle Hamburg 236

Gericht des Befehlshabers der Panzerschiffe bzw. Schlachtschiffe 236

Gericht des Befehlshabers der Sicherung West 236

Gericht des Führers der U-BooteAusbildungsflouillen 236

Gericht des Kommandeurs der Kriegsgefangenen im Wehrkreis VI 236

Gericht des Kommandeurs des Luftverteidigungsgebiets Hannover 237

Gericht des Kommandierenden Generals und Befehlshabers im Lufigau VII 236

Gericht des Kommandierenden Generais und Befehlshabers im Lufigau XI 236

Gericht des Kommandierenden Generals und Befehlshabers im Luftgau XIL/XIII 236
Gericht des Kommandierenden Generals und Befehlshabers im Luftgau XIV 236

Gericht des Oberkommandos der Kriegsmarine 235

Gerichte der 2. Admirale der Nordsee- und der Ostseestation 236

Gerichte der Kommandanturen der Befestigungen am Niederrhein 236

Gerichte der Küstenbefehlshaber westliche Ostsee, Deutsche Bucht 236

Gerichte der Marine-Bereichskommandanten Schleswig und Eckernförde 236

Gerichte der Wehrmachtkommandanturen Berlin, Dïsseldorf und Hamburg 235

Gerichtshof zur Entscheidung der Kompetenzkonflikte. preuB. 245

Germanische Leitstelle 117

Germanische zeitgeschichtliche Sammlung. Hannover 85

Gesamtverband Deutscher Handwerker. Kaufleute und Gewerbetreibender 509

Gesandtschaft

- Agram 50

- Athen 50

- beim Heiligen Stuhl. bayerische 53

- Belgrad 50

- Bern 50

- Budapest 50

- Bukarest 50

- Helsinki 50

- Kabul 50

- Kopenhagen 50

- Kowno 50

- Lissabon 50

- Luxemburg 50

- Oslo 51

- Prag 51

- PreBburg 51

- Reval 51

- Riga 51

- Sofia 51

- Stockholm 51

- Teheran 51

- Tirana 51

- bremische, Berlin 53

-, hamburgische, Berlin 23

-, lübeckische. Berlin 54

Gesandtschaften, bayerische. Berlin. Darmstadt. Karlsruhe 54

Geschäftsführende Reichsregierung Dönitz 6. 326

Geschäftsgruppe Devisen des Beauftragten für den Vierjahresplan 358

Geschäftsgruppe Ernährung des Beauftragten für den Vierjahresplan 360

Gesellschaft der Wissenschaften. Göttingen 286 
Gesellschaft für Deutsche Kultur. Thein. 36

Gesellschaft für deutsche Kultur 310

Gesellschaft für öffentliche Arbeiten (Öffa) 327

Gesellschaft für Senderechte 316

Gesellscinaft für Seuchenbekämpfung 121

Gesellschaft für Textil- und Lederverwerung 121

Gesellschaft für Theatergeschichte 320

Gesellschaft Reichsautobahnen 372

Gesellschaft Süd- und Nordwestkamerun 43

Gesellschaft zur Förderung der Westfälischen Wilhelms-Universität 296. 297

Gesellschaft zur Förderung und Pflege deutscher Kulturdenkmäler 133

Gestapo-Lager Brauweiler 148

Gesundheitsamt

- Ahrweiler 241

- Alzey 241

- Backnang 241

- Bad Ems 241

- Bad Kreuznach 241

- Bergzabern 241

- Birkenfeld 241

- Bremen 241

- Germersheim 241

- Koblenz 241

- Kusel 241

- Landau 242

- Ludwigshafen 242

- Melle 242

- NeustaduWeinstraße 242

- Neuwied 242

- Nordhorn 242

- Paderborn 213

- Pirmasens 242

- Recklinghausen 242

- Simmern 242

- Speyer 242

- St. Goar 242

- St Goarshausen 242

- Trier 242

- Villingen 242

- Westerburg 242

- Witdich 242

- Worms 242

- Zell/Mosel 242

Getreidewirtschaftsverband

- Kurhessen 399

- Schleswig-Holstein 398

- Westmark 400

- Württemberg 398

Gewerbesteuer-Berufungsausschuß 353

Gewerkschaft Wintershall 88

Gewerkschaftsbund der Angestellten 474

Ghetto Theresienstadt 141, 142, 144, 145. 146. 148, 264, 342
Girokontor der Reichshauptbank 345

Gladbacher Gewerbebank 223

Görreshaus 211

Grenzpolizeikommissariate Emden. Emmerich. Kleve. Lörrach. Singen und Waldshut 154

Grenzpolizeiposten Niebüll 154

Grenzpolizeischule Fürstenberg 125

Großes Militärwaisenhaus Potsdam 431

Gymnastikschulen .Loheland" und Schwarzerden 35

Häftlingskrankenbau Neuengamme 132

Hamburg-PreuBische Hafengemeinschaft GmbH 13

Handelshochschule

- Berlin 266

- Königsberg 266

- Mannheim 288, 289

- Nürnberg 305

Handelskammer

- Aachen 78

- Stuttgart 9

Handelspolitischer AusschuB 383

Handelsstatistisches Amt Hamburg 394

Handwerkskammer Dormund 33

Handwerkskammer Wiesbaden 412

Hannoverscher Königsbund 84

Hans-Schemm-Hochschule. Müncher-Pasing 307

Harpener Bergbau A.G. 245

Hauptabteilung fur Sippenkunde und Volis. pflege 176

Hauptabteilung für völkische Schutzarbeit 175

Hauptamt der SS 117

Hauptamt fur Agrarpolitik der NSDAP 367. 469

Hauptamt für Beamte der NSDAP 456, 520

Hauptamt für Erzieher der NSDAP 456. 520. 522

Hauptamt für Kommunalpolitik der NSDAP 456. 470

Hauptamı für Kriegsopfer der NSDAP 456. 517

Hauptamt für Technik der NSDAP 456, 523

Hauptamt fur Volksgesundheit der NSDAP 456. 490.518

Hauptamt für Volkstumsfragen der NSDAP 459

Hauptamt für Volkswohlfaht der NSDAP 456. 515.517

Hauptamt Kriegsschiffbau 436

Hauptami Ordnungspolizei 126

Hauptamt Sicherheitspolizei 121

Hauptamt SS-Gericht 237 
Hauptamt Verwaltung und Wirtschaft der SS 120

Hauptarchiv der NSDAP 1. 372,473

HauprausschuB Flugzeugbau 363

HauptausschuB Kraftahrzeuge 363

HauptausschuB Maschinen 363

HauptausschuB Munition 363

HauptausschuB Pulver und Sprengstoff 363

HauptausschuB Schienenfahrzeuge 363, 387

HauptausschuB Waffen 363

irauptfilmstelle des Reichsluftfahrtministeriums 439

Hauptfürsorge- und Versorgungsstelle Detmold 19, 419

Hauptgeschäftsführung der Reichskulturkammer 309

Hauptgeschäfusleitung der Berliner Gauzeitung "Der Angriff 479

Hauptprüfungsamt der Deutschen Reichsbahn 369

Hauptredaktion des Handwönerbuchs des Grenz- und Auslandsdeutschtums 178

Hauptstaatskasse Darmstadt 18

Hauptstaatskasse Hamburg 341

Hauptureuhandstelle Ost 323, 342. 359, 365

Hauptvereinigung der deutschen Brauwirschaft 387

Hauptvereinigung der deutschen Fischwirschaft 386

Hauptvereinigung der deutschen Gartenbauwirtschaft 386

Hauptvereinigung der deutschen Getreideund Futtermittelwirtschaft 386

Hauptvereinigung der deutschen Kartoffelwirtschaft 386

Hauptvereinigung der deutschen Milch-, Fettund Eierwirschaft 386

Hauptvereinigung der deutschen Viehwirtschaft 386

Hauptvereinigung der deutschen Wein- und Trinkbranntweinwirtschaft 387

Hauptvereinigung der deutschen Zucker- und SüBwarenwirtschaft 387

Hauptverkehrsdirektion Brüssel 402

Hauptvermessungsabteilung Hamburg 23

Hauptverwaltung der Reichskreditkassen 346

Haus der Deutschen Forschung 272

Haus der Vorzeit, braunschw. 271

Haus des Deutschen Rechts 295

Hausgefängnis des Gestapa 125

Hausintendantur der Kanzlei des Führers 456

Havel-Institut 125

Heeresausbildungsabteilung des OKH 433

Heeresdienststelle 6, Regensburg 446

Heeresdienststelle 9. Köln 444

Heeresdienststelle 10445

Heeresfilmstelle 429
Heeresgruppe „Obenthein 114

Heeresgruppe ..Weichsel " 114

Heerespersonalamt 435

Heeresversuchsanstalt Peenemünde 115

Heeresverwaltungsamt 435

Heereswaffenamt 435

Heil- und Pflegeanstalt

- Andernach 169

- Aprach 242

- Bayreuth 169

- Bedburg-Hau 170

- Berlin-Wittenau 169

- Bernburg 169

- Brandenburg 169

- Bremen-Hemelingen 166

- Dortmund-Aplerbeck 169

- Ecksberg 105

- Eglfing-Haar 170

- Eichberg 170, 173

- Eickelborn 169

- Galkhausen 170

- Goddelau 170

- Göttingen 170

- Grafeneck 171

- Gütersloh 169

- Hadamar 170, 171

- Haina 103

- Hamburg-Langenhorn 171

- Herborn 171

- Illenau 171

- Kaufbeuren-Irsee 171

- Klingenmünster 110

- Königslutter 73. 172

- Lengerich 169

- Lindenhaus 172

- Loben/Oberschlesien 166

- Lüneburg 91. 172

- Marburg/Lahn 103, 172

- Merxhausen 103, 172

- Obrawalde 169

- Pfaffenrode 171

- Saffig bei Andernach 509

- Scheuern 170, 172

- Schussenried 70

- Waldniel 172

- Warstein 169

- Wehnen 72

- Weilmünster 170, 172

- Weinsberg 70

- WeiBenau 70

- Wiesloch 166, 172

- Winnenthal 70

- Wunstorf 173

- Zwiefalten 70

Heilpraktikerbund 462

Heimatwerk Baden 332, 424

Heimarwerk Hessen-Nassau 423 
Heimstätte Schleswig-Holstein 395

Heimstätten. Bayerische 108

Heimstättenamt der DAF 508

Heinkel-Flugzeugwerke 437

Heiratsamt der SS 119

Henschel-Flugzeugwerke 437

Hermann-Göring-Akademie für Forstwissenschaft Hann. Münden 86, 295, 368

Hermann-Göring-Meisterschule für Malerei 338

Hermann-Göring-Stifung 392

Hermann-Göring-Werke s. Reichswerke

Herold-Verlag 465

Herrenclub 474

Herz-Jesu-Priester-Kongregation 222

Hilfskasse der NSDAP 463

Hilfswerk ,Mutter und Kind" der NSV 22, $70,77,515,516,517$

Hilfszug Bayern 462

Hiswrische Kommission der Bayerischen Akademie der Wissenschaften 306

Historische Kommission Reichsführer SS 115

Hitlerjugend (HJ, mit BDM und Deutschem Jungvolk) $3,12,14,20,22,23,30,33$. $34,44,81,86,93,95,98,143,164,209$. 212. 222, 223, 226, 269, 270. 271. 278, 304, 316, 318, 319. 333, 350. 353, 449. $450,461,462,463,464,475,479,486$, 497-501

HJ-Bann

- Allgäu 501

- Alsfeld-Lautertach (304) 500

- Aschaffenburg 500

- Augsburg-Stadt und -Land 501

- Bad Kissingen 500

- Bonn (160) 500

- Donauwörth 501

- Düren (161) 500

- Frankfurt 500

- Gelnhausen 500

- GieBen 500

- Günzburg 501

- Habfur 500

- Herborn 500

- Karlstadt-Marktheidenfeld 500

- Kitzingen-Gerolzhofen 500

- Limburg 500

- Lohr 500

- Memmingen 501

- Neuburg/Donau 501

- NeustaduSaale 500

- Nördlingen 501

- Offenbach 500

- Pforzheim 499

- Schweinfur 500

- Siegen (138) 501

- Wertach 501
HJ-Bann (Fors.)

- Würzburg-Stadt und -Land

- Ziegenhain 500

HJ-Banne 119, 122 und 364501

HJ-Obergericht 498

Hochschularbeitsgemeinschaft für Raumforschung 291

Hochschule für Lehrerbildung

- Esslingen 307, 505

- Lübeck 27

- Weilburg (Lahn) 307

- Würzburg 308

Hochschule für Musik Köln 338

Hochschule für Musikerziehung und Kirchenmusik Berlin 338

Hochschule für Politik 275

Hochschulgnuppe des NSDStB

- Aachen 505

- Frankfurt 506

- GieBen 506

- Hamburg 506

- Hannover 506

- Köln 506

- Tübingen 507

- Würzburg 507

Hochschulkommission der NSDAP 294

Hochschulring des NS-Altherrenbundes Esslingen 505

Hochschulverband 281, 282, 286, 288, 291

Hochschulverwaltung. Hamburg 25

Höchster SS- und Polizeiführer Italien 440

Höherer SS- und Polizeiführer

- Fulda-Werra im Wehrkreis IX, Kassel 137

- Main im Wehrkreis XIII. Nürnberg 138

- Mitte im Wehrkreis XI, Braunschweig 22

- Nordsee im Wehrkreis X, Hamburg 137

- Rhein(- Westmark) im Wehrkreis XII,

Wiesbaden 138

- Süd im Wehrkreis VII. München 97, 137. 174

- Südwest im Wehrkreis V. Stungar 136

- West im Wehrkreis VI. Düsseldorf 137. 442

Höheres Kommando Saarpfalz 449

Hölderin-Gesellschaft 269

Hohe Schule der NSDAP 462. 466, 476

Hygiene-Instirut der Waffen-SS 118

Hygienisch-bakteriologische Untersuchungsstelle Südost der Waffen-SS. Auschwitz 118

I.G. Farbenindustrie A.G. 115, 264, 378, 431

- (BASF) Ludwigshafen 352

- (Bayer) Leverkusen 509

Ibero-amerikanisches Institut 276

Indag - Industrieverwaltungs - A. G. 347 
Industrie- und Handelskammer

- Augsburg 397

- Bayreuth 108

- Bremen 26

- Detmold 20

- Kassel 88

- Oldenburg 72. 397

- Osnabrïick 95

- Ostwestfalen 33

Industriebeteiligungsgesellschaft mbH 375 Infanterie-Division 465233

Infanterie-Divisionen 7. 10, 17, 20, 22. 30. 33, 34 und 35449

Infanterieregiment Nr. 1822

Infanterieregimenter Nr. 19, 20, 61, 63450

Informationsstelle für technisches Schriftum 301

Informationsstellen des Auswärtigen Amtes 48

Innenbehörde Bremen 73

Innenministerium. bad. 71

Innenministerium. bayer. 68, 136

Innenministerium, braunschw. 72

Innenministerium, oldenburg. 71. 152

Innenministerium, preuB. 57, 67, 329

Innenministerium, thüring. 59

Innenministerium, würtlemberg. 66. 69, 303

Innere Mission 31

Inspekteur der Grenz- und Wacheinheiten 117

Inspekteur der Heimschulen 117, 278, 279

Inspekteur der Landesbefestigungen West 449

Inspekteur der Sicherheitspolizei

- Düsseldorf 139

- Hamburg 139

- Münster 33

- Rhein-Westmark 158, 159

Inspekteur für Statistik 115, 116

Inspekteur für technische Ausbildung und Geräte des NSKK 496

Inspektion der (bayerischen) uniformierten Staatspolizei 134

Inspektion der Konzentrationslager 127

Inspektion der SS-Verfügungstruppe 117

Institut der Elsaß-Lothringer im Reich 283

Institut für angewandte Wirtschaftswissenschaft 305

Institut für Anthropologie, menschliche Erblehre und Eugenik 272

Institut für Archivwissenschafi 12

Institut für Auslandsbeziehungen 176

Institut für Auslandskunde 289, 296

Institut für Chemische Technik 303

Institut fir das Gärungsgewerbe, Berlin 365

Institut für Deutsche Musikforschung 338
Institut für deutsche Studentengeschichte, Würzburg 503

Institut für Deutsche Wirschaftspropaganda 315

Institut für Ert- und Rassenpflege 285

Institut für Erbbiologie und Rassenhygiene 283, 292

Institut für Fernmelde- und Hochfrequenztechnik 302

Institut für Flugzeugbau 302

Institut für Gemeinwohl $\mathbf{2 8 3}$

Institut für Grenz- und Auslandsdeutschtum 287, 293

Institut für Grenz- und Auslandsstudien 178

Institut für Handwerkswissenschaft 283

Institut für Hochspannungstechnik 302

Institut für Humangenetik. Münster 297

Institut für Infektionskrankheiten ,Robert

Koch" 165

Institut für Jagdkunde 385

Institut für Jugendkunde 27 I

Institut für Kautschukforschung 285

Institut für Konjunkturforschung 379. 431

Institut für Krafufahrwesen und Fahrzeugmotoren 303

Inscitut für Krafifahrwesen 300

Institut für Kulturpflanzen, Tuttenhof 365

Institut für Luftahrtmedizin 439

Institut für Organisationslehre und Soziologie 296

Institut für Osteuropäische Wirtschaft 178

Institut für Ostseefischerei 386

Institut für politische Erziehung 284

Institut für Psychologie 302

Institut für Rassenhygiene 294

Institut für Rassenkunde 284

Institut für Rundfunkwissenschaft 284

Institut für Runenforschung 285

Institut für Sozialforschung 283

Institut für Staatsforschung, Beriin 266

Institut für Textiltechnik 300

Institut für Vơlker- und ländliche Biologie 284

Institut für Völkerkunde 292

Institut für Volks- und Landesforschung 290

Institut für Vor- und Frühgeschichte 292

Institut für Wehpolitik, Berlin 266

Institut für wehrwissenschaftliche Zweckforschung 115, 116

Institut für Weltwirtschaft, Kiel 266, 431

Institut für Wirschaftsbeobachtung 305

Institut für wïrtembergische Wirschaft 299

Institut für Zeitungskunde 292

Institut für Zeitungswissenschaft 305

Institut zur Erforschung der Judenfrage 466 , 476 
Institut zur Erforschung des Deutschen Volksnums im Süden und Südosten Südost-Institut 295

Institut zur Erforschung des jüdischen Einflusses auf das deutsche kirchliche Leben. Eisenach 293

Interministerieller LuftkriegsschädenausschuB 261

Internationale Gesellschaft für kaufmännisches Bildungswesen 380

Internationale Transportarbeiterföderation 123, 143

Internationaler Eisenbahnerverband 369

Internationaler Gewerkschaftsbund 123

Intermationaler Sozialistischer Kampfbund 123

Internationales Rotes Kreuz 45, 46 Interradio s. Deutsche Auslandsrundfunk A.G.

Invalidenhaus Bertin 431

Israelitische Gartenbauschule Ahlem 85

Israelitische Kultusvereinigung Offenbach 17

Israelitischer Lehrerverein, hess. 17

Israelitisches Hospital Worms 17

Jägerstab 362, 437

Jagddivisionen, 2., 3. und 4. 451

Jagdfliegerführer Süddeutschland 451

Jagdgeschwader Nr. 1, 26, 53 und 77451

Japanisch-deutsches Kulturinstitut Berlin 295

Jesuitenorden 211

Johann-Wolfgang-Goethe-Universität s. Universität Frankfun

Jüdisches Kulturwerk 87

Jugendbehörde Hamburg 77

Jugendbund "Esra", Wiesbaden 482

Jugendfuihrer des Deutschen Reiches 76

Jugendgefängnis MarienschloB 196

Jugendgefängnis Niederschönenfeld 195

Jugendschulzlager Moringen/Krs. Northeim 129, 219

Julius-Maximilians-Universität s. Universität Würzburg

Jungdeutscher Orden 84, 143, 145, 422, 423

Jungmädelbund (JM) im BDM 498, 501

Junkers-Flugzeugwerke 437

Justizministerium, bad. 184

Justizministerium, bayer. 184

Justizministerium, hess. 185

Justizministerium, oldenburg. 185

Justizministerium. preuB. 183

Justizministerium, würtemberg. 184

Justizprïfungsstelle Düsseldorf 188

Justizverwaltung Bremen 183

Justizvollzugsanstalt

- Aachen 190

- Aichach 205
Justizvollzugsanstalt (Forts.)

- Berlin-Plötzensee 191. 227. 353

- Bernau/Oberbayern 191

- Bielefeld 191

- Bonn 191

- Brandenburg-Görden 227

- Braunschweig 203

- Darmstadi 192

- Detmold 192

- Düsseldorf-Derendorf 192

- Duisburg-Hamborn 192

- Emden 192

- Essen 192

- Flensburg 192

- Frankenthal 192

- Frankfurt-Hammelsgasse 192

- Frankfurt-Höchst 193

- Frankfurt-Preungesheim 193

- Freiburg 193

- Hagen 193

- Hamburg-Fuhisbüttel 193

- Hamm 193

- Herford 193

- Kaisheim 205

- Kiel 194

- Kleve 194

- Köln 194

- Landsberg 194, 205

- Laufen-Lebenau 205

- Leipzig II 227

- Lübeck 194

- Mannheim 195

- Minden 195

- München-Stadelheim 195, 205

- Niederschönenfeld 205

- Oldenburg 195

- Rothenfeld 205

- Saarbrücken 196

- Ulm 196

- Vechta 197

- Waldheim 227

- Witalich 197

- Wolfenbüttel 197. 203

- Wuppertal 197

- Zweibrücken 197

Justus-Liebig-Universität s. Universität Gieben

Kämmereiamt Lübeck 335

Kaiser-Wilhelm-Gesellschaft zur Förderung der Wissenschaft 12,61, 260, 272, 306, 325,329

Kaiser-Wilhelm-Institut für ausländisches öffentliches Recht und Völkerrecht 249

Kaliprüfungsstelle 384

Kammer für die steuerberatenden Berufe 327

Kammergericht 194, 197, 198, 199 
KampfausschuB gegen Schmutz und Schund 506

Kampfbund der Deutsch-Österreicher 78

Kampfbund der deutschen Architekten und Ingenieure 70

Kampfbund des gewerblichen Mittelstandes 83

Kampfbund für Deutsche Kultur 78, 282. 310, 466

Kampfbund gegen den Faschismus 68, 123

Kanzlei des Führers 166, 358, 456

Kanzlei des Generalgouverneurs 55

Kanzlei Rosenberg 466

Karl-Wahl-Stiftung 487

Karpathen-Öl A.G. 378

Kartell der Deutschen Akademien 306

Kartellgericht 244

Kartoffelwirtschaftsstelle Westfalen 398

Kassenärzliche Vereinigungen 252

Katholische Aktion 160

Katholischer Jungmännerverband 83, 422

- Paderborn 244

Karholisches Arbeitswerk 424

KdF s. NS-Gemeinschaft „Kraft durch Freude

Kinderheilerziehungsheim Idstein-Kalmenhof 171

Klemm-Flugzeugwerke 437

Klöckner-Konzern 357

Klosterkammer Hannover 29

Knappschafts-Oberversicherungsamt Clausthal 419

Kodak A.G. 247

Kolonialgeographischer AusschuB des Reichsforschungsrates 292

Kolonialpolitisches Amt der NSDAP 280. 294, 469

Kolonialpolitisches Institut 295

Kommandant des Führerhaupequartiers 428

Kommandantur der Befestigungen am Niederthein 236

Kommandantur der Befestigungen Eifel/Saarpfalz 236

Kommandanturen der Befestigungen Eifel, Niederthein, Obenthein, Saarpfalz 449

Kommandeur der Gendarmerie Saarbrücken 161

Kommandeur der Gendarmerie, hess. 17

Kommandeur der Kriegsgefangenen im Wehrkreis VI 236

Kommandeur der Schutzpolizei Osnabrück 162

Kommandeur des Streifendienstes im Wehrkreis VI 444

Kommando Leitmeritz des Konzentrationslagers Fosseribürg 131
Kommando Niederhagen-Wewelsburg des Konzentrationslagers Buchenwald 133

Kommandoamt der Allgemeinen SS 118

Kommandoamt der Waffen-SS 118

Kommandos Baden-Oas, Dautmergen, Erzingen, Haslach im Kinzigtal, Heppenheim, Hessenthal, Iffezheim. Kochendorf. Leonberg, Neckarelz. Neckargerach, Schörzingen, Schomberg. Spaichingen. Untermixingen. Vaihingen und Walldorf des Konzentrationslagers Natzweiler 133

Kommandos Ahlem, Drütre, Eidelstedt, Hamburg-Sasel und -Tiefstaak, Helmstedt. Husum, Kaltenkirchen, Ladelund, Schandelah, Stöcken, Versen, Porta Westfalica, Lengerich und Watensted des Konzentrationslagers Neuengamme 132

Kommandostab Reichsführer SS 118

Kommandostab Volkssturm der Gauleitung Westmark 486

Kommissar der Freiwilligen Krankenpflege 165

Kommissar für den Archivschutz 62

Kommissar für die Verwaltung feindlichen

Vermögens im Generalgouvernement 188

Kommission für die Donauschiffahr 371

Kommission für die Elbschiffahn 371

Kommission zur Bewahrung von Zeitdokumenten 262

Kommission zur Prüfung der Seehandlung 338

Kommunallandtag Hohenzollern 103

Kommunistische Arbeiterpartei Deutschlands (KAPD) 59

Kommunistische Internationale (Komintern) 59, 123

Kommunistischer Jugendvertand Deutschlands (KJVD) 68, 123, 195, 510

Konsulate Antwerpen, Apenrade, Bagdad, Basel. Chunking, Czernowitz, Galatz, Genf, Göteborg, Graz, Izmir, Kiew, Klagenfur, Krakau, Kronstadt, Lemberg. Leningrad, Liverpool, Lodz, MaastrichiHeerlen, Malmö, Memel, Odessa, Reykjavik, Rotterdam, San Francisco, Täbris, Temesvar, Windhuk und Winnipeg 52

Konsulate, württemberg., Bremen und Hamburg 54

Kontor für Wertpapiere der Reichsbank 345

Konversionskasse für deutsche Auslandsschulden 347

Konzentrationslager

- .Am Hochkreuz" Porz-Gremberghofen 130

- Ankenbuck/Baden 128

- Auschwitz 92, 118, 141, 144, 155

- Bergen-Belsen 130, 141

- Börgermoor 128 
Konzentrationslager (Forts.)

- Brauweiler bei Köln 128

- Bremen-Langlütjen 128

- Buchenwald 133, 137, 155, 238

- Dachau 116, 130, 133, 155, 216, 223. 463

- Esterwegen/Emsiand 95. 128

- Flossenbürg 131, 237

- Hamburg-Fuhisbiutul 129

- Heuberg/Krs. Stetten 129

- Kislaw/Krs. Bruchsal 15, 129

- Lichtenburg 129

- Lublin-Maidanek 136, 137

- Mauthausen 136, 155, 223

- Moringen 84, 129, 155

- Natzweiler/ElsaB 116, 131, 133

- Neuengamme 132, 155, 246

- Neusustrum 128

- Niederhagen-Weweisburg 133

- Oranienburg 67, 127

- Osthofen/Krs. Worms 130

- Ravensbrück 463

- Sachsenhausen 133,141, 166

- Ulm-Kuhberg 128

- Wuppertal-Beyenburg 83

- Wuppertal-Kemna 130, 204, 226, 471

Kostenprüfstelle Bremen 335

KPD 4, 22, 26, 59, 68. 84, 88. 92, 111. 122. $123,139,142,143,147,148,149,150$. 151. 152. 154. 157, 158, 159, 160. 184. $185,194,199,208,210,219,221,225$. $227,229,232,244,256,257,289,449$. $474,507,509$

Krebs- und Lupus-Stiftung 296

Kreisbauernschaft

- Hessen-Nassau-Süd 401

- Niederberg 401

- Nürnberg 399, 401

Kreisernährungsamt

- Bonn 401

- Düsseldorf-Meumann 401

- Siegburg 401

Kreisfrauenschafisleitungen Augsburg, Bad Hersfeld, Donauwörth, Herford, Kempten, Kumbach, Ludwigsburg, Marktoberdorf, Mernmingen, Neu-Ulm, Neuburg, Nördlingen, Sonthofen und Stuttgart 502

Kreisgericht der NSDAP

- Aachen 483

- Aalen 491

- Bingen 483

- Bitburg 483

- Bremen 488

- Crailsheim 491

- Ehingen 491

- Heidenheim 491

- Öhringen-Künzelsau 491

- Paderborn 489
Kreisgericht der NSDAP (Forts.)

- Ulm 491

- Waiblingen 491

Kreisleitung der NSDAP

- Aachen-Stadt und -Land 483

- Aalen 491

- Alsfeld-Lautertach 482

- Altörting 485

- Altona 482

- Amberg 479, 479

- Aschaffenburg-Alzenau 484

- Augsburg-Stadt 486

- Augsburg 487

- Backnang 491

- Bad Kissingen-Münnerstadt 484

- Bensheim 482

- Berchresgaden-Laufen 485

- Bergisch-Gladbach 483

- Biedenkopf-Dillenburg 482

- Bochum 490

- Böblingen 491

- Bonn 483

- Borken-Bocholt 489

- Braunschweig-Stadt und -Land 488

- Bremen 488

- Brückenau-Hammelburg 484

- Büdingen 482

- Dachau 485

- Deumold-Lemgo 489

- Diez 483

- Dinkelsbühl 481

-. Duisburg 480

- Ebern 484

- Ebersberg 485

- Eichstäu 481

- Ennepe-Ruhr 490

- Eschwege 484

- Esslingen 491

- Euskirchen 483

- Eutin 486

- Feuchtwarigen 481

- Frankenberg/Eder 484

- Freiburg der NSDAP 478

- Freising 485

- Fritzlar-Homberg 484

- Fürstenfeldbruck 485

- Fürth 481

- Fulda 484

- Geilenkirchen 483

- Gelnhausen 482, 484

- Göppingen 491

- Göttingen 219, 488

- Günzburg 487

- Hanau 482

- HaBfurt 484

- Heilbronn 491

- Herford 489 
Kreisleitung der NSDAP (Fons.)

- Herne-Castrop-Rauxel 490

- Hersbruck 481

- Höxter-Warburg 489

- Hofgeismar 484

- Hünfeld 484

- Ingolstadt 485

- Jülich 483

- Kassel 484

- Kitzingen-Gerolzhofen 484

- Köln 483

- Königshofen-Hofheim 484

- Krefeld-Kempen 480

- Kronach 479

- Landsberg/Lech 485

- Lauf an der Pegnitz 481

- Limburg-Unierlahn 482

- Lippstadt 489

- Lohr-Gemünden 484

- Ludwigsburg 491

- Lidinghausen 489

- Luxemburg 483

- Maintaunus-Obertaunus (Bad Soden) 482

- Marburg 484

- Marktheidenfeld-Karistadt 484

- Marktoberdorf 487

- Mayen 483

- Melsungen 484

- Memmingen 487

- Miluenberg-Obernburg 484

- Mōnchengladbach 480

- Mühldorf 485

- München 485

- Münster-Warendorf 489

- Neustadt (Aisch) 481

- Neustadi-Mellrichstadt 484

- Nördlingen 487

- Nürnberg-Stadt und -Land 481

- Oberiahn-Usingen (Weilburg) 482

- Oberwesterwald (Westerburg) 482

- Ochsenfurt 484

- Öhringen-Künzelsau 491

- Rastart 478

- Rheingau (Rüdesheim) 482

- Rosenheim 485

- Rotenburg/Fulda 484

- Rothenburg ob der Tauber 481

- Schlïchtern 482

- Schongau 485

- Schwabach 481

- Schweinfun 484

- Siegburg 483

- Sonthofen 487

- St Goarshausen 482, 483

- Starnberg 485

- Traunstein 485

- Trier-West-Land 483
Kreisleitung der NSDAP (Fonts.)

- Ulm 491

- Vaihingen 491

- Wasserburg/lnn 485

- Wegscheid 479

- Weilheim 485

- Wesermüinde 488

- Wetterau (Friedberg) 482

- Wetzlar 482

- Wiesbaden 482

- Witzenhausen 484

- Wolfhagen 484

- Würzburg-Stadt und -Land 484

- Ziegenhain 484

Kreisleiung Nord und Kreisreferentin Nord für Studentinnen des NSDStB $\mathbf{5 0 6}$

Kreismusikerschafi Wiesbaden 313

Kreiswaltung Alsfeld-Lauterbach der NSV 517

Kreiswaltung Augsburg der DAF 514

Kreiswaltung Augsburg der NSV 517

Kreiswaltung Bad Hersfeld der DAF 515

Kreiswaltung Bad Hersfeld der NSV 517

Kreiswaltung Berchtesgaden-Laufen der DAF 514

Kreiswaltung Bergstrabe der DAF 514

Kreiswaitung Detmold der DAF 489

Kreiswaltung Detmold der NSV 489

Kreiswaltung Dinslaken des NSLB 522

Kreiswaltung Frankfurt der DAF 514

Kreiswaltung Freiburg der DAF 514

Kreiswaltung Friedberg/Hessen des NSLB 522

Kreiswaltung Göppingen der DAF 515

Kreiswaltung Günzburg der DAF 514

Kreiswaltung Günzburg der NSV 517

Kreiswaltung Hannover des NSLB 522

Kreiswaltung Heidelberg der DAF 515

Kreiswaltung Kehl der DAF 514

Kreiswaltung Ludwigsburg der DAF 515

Kreiswaltung Marktoberdorf der NSV 517

Kreiswaltung Markaoberdorf der DAF 514

Kreiswaltung Memmingen der DAF 514

Kreiswaltung Memmingen der NSV 517

Kreiswaltung Nordlingen der DAF 514

Kreiswaltung Nordlingen der NSV 517

Kreiswaltung Öhringen-Künzelsau der DAF 515

Kreiswaltung Offenbach der DAF 514

Kreiswaltung Offenbach der NSV 517

Kreiswaltung Regensburg der DAF 514

Kreiswaltung Sonthofen der DAF 514

Kreiswaltung Sonthofen der NSV 517

Kreiswaltung Traunstein der NSKOV 518

Kreiswaltung Ulm der DAF 515

Kreiswaltung Waiblingen der DAF 515

Kreiswaltung Wetterau der NSV 517 
Kreiswaltung Welzlar der DAF 514

Kreiswaltung Wiesbaden der DAF 514

Kreiswaltung Zabern der DAF 514

Kriegsarchiv der Waffen-SS 118

Kriegsgefangenen-Mannschafts-Stammlager (Stalag) VI A. VI G, VII A. XII A. XIII C 448

- VI B und C 433

Kriegsgefangenen-Offizierslager (Oflag) VII D und XI 448

Kriegsgeschichtliche Forschungsabteilung der SS 118

Kriegsmarinedienststelle Bremen 453

Kriegsmarinedienststelle Hamburg 236, 453

Kriegsschädenamt für die Seeschiffahrt 388

Kriegswissenschaftliche Abteilung der Lufiwaffe 437

Kriminalbiologische Forschungsstelle 166

Kriminalmedizinisches Zentralinstitut 124

Kriminalpolizeileitstelle

- Düsseldorf 155

- Frankfur/Main 155

- Hannover 155

- Köln 155. 156

- München 156

- Stutgart 156

Kriminalpolizeistelle

- Aachen 155

- Darmstadt 155

- Karlsruhe 155, 156

- Kassel 156

- Nürnberg 156

- Saarbrücken 155

- Trier 100, 155

Kriminaltechnisches Institut der Sicherheitspolizei 124

Krolloper, Berlin 338

Krupp, Fa. Fried. 133, 209. 243. 357. 450

Kuluministerium, würtemberg. 268. 298, 303. 304

Kulturpolitische Pressekonferenz 264. 309

Kulturpolitisches Archiv des Amtes Rosenberg 467

Kulturvertand, braunschw. 271

Kultusministerium, bad. 15, 268

Kultusministerium, bayer. 267, 305, 507

Kultusministerium, braunschw. 270

Kultusministerium, oldenburg. 269

Kultusministerium, preuB. 259, 260, 265. 266, 276

Kunstakademie

- Düsseldorf 338

- Kassel 338

- München 268

Kunsthistorische Forschungsstelle Paris 338

Kunsthistorisches Institut Florenz 338

Kunsthochschule Hamburg 354
Kuratorium für deutschen Volkswinschaftsdienst e.V. 315

Kyffhäuser-Bund 5, 474

Lagerhaus-Gesellschaft Bremen 393

Lanoesamt für Familienguter, preuB. 239

Landesarnt für Vor- und Frühgeschichte. thein. 292

Landesanstait für den Physikunterricht, württemberg. 279

Landesanstalt für Erziehung und Unterricht. württemberg. 279

Landesanstalt für Wasser-, Boden- und Lufthygiene, preuB. 166

Landesarbeitsamt

- Bayem 14, 4 !3

- Hessen 424

- Niedersachsen 31. 413

- Rheinland 79, 84, 413

- Schleswig-Holstein 413

- Südwesıdeutschland 70

- Westfalen-Lippe 20, 176

- Westmark 415

- Württemberg 414

Landesarbeitsanstalt Breitenau 103

Landesarbeitsgericht Freiburg 250

Landesarbeitsgericht Hannover 250

LandesausschuB Hohenzollern 103

Landesbank Hohenzollern 103

Landesbank Schleswig-Holstein 395

Landesbank. Hessische 17

Landesbauernschaf

- Baden 331. 365, 399

- Bayern 365. 399

- Bayreuth 365

- Hannover 399

- Hessen-Nassau 365. 399

- Kurhessen 365. 399

- Niedersachsen 365

- Rheinland 399

- Saarpfalz/Westmark 400

- Schleswig-Holstein 400

- Weser-Ems 400

- Westfalen 21

- Wïrtemberg 339, 391, 401

Landesbühne Coburg 268

Landesbühne Württemberg 9

Landesdienststelle Braunschweig des Deutschen Gemeindetages 76

Landesdienststelle Hamburg des Deutschen Gemeindetages 23

Landesdienststelle Oidenburg-Bremen des Deutschen Gemeindetages 75

Landeserbhofgenicht, preuB. 239

Landesernährungsamt

- Bremen 398

- Hamburg 398 
Landesernährungsamt (Forts.)

- Hannover 398

- Hessen 399

- Oldenburg 96

- Schleswig-Holstein 395

- Weser-Ems 398

- Westfalen 398

- Württemberg 398

Landeserziehungsanstalt Bevern 77

Landesfinanzamt

- Baden 340-345

- Berlin-Brandenburg 340

- Darmstadt 339

- Düsseldort 340

- Hambung 342

- Hannover 342

- Hessen 340

- Kassel 343

- Köln 343

- Mainfranken 344

- München 344

- Nordmark 344

- Nürnberg 344

- Weser-Ems 344

- Westfalen 345

- Westmark 344, 345

- Würtiemberg 345

Landesforstamt Westmark 10

Landesfürsorgestelle für Kriegsbeschädigte und Hinterbliebene, Bückeburg 22

Landesfürsorgeverbände Hechingen und Sigmaringen 248

Landesgefängnis Mannheim 185

Landeshauptkasse Bremen 335

Landeshauptkasse, hess. 18

Landeshypothekenbank, hess. 17

Landesinstitut für Bienenforschung, hannov. 32

Landesjugendamt Braunschweig 76

Landeskirchenamt, hannoversches 30

Landeskommissäre Freiburg, Kartsruhe, Konstanz und Mannheim 112

Landeskommunalverband Hohenzollern 103

Landeskonservator Hohenzollern 103

Landeskonservator Schleswig-Holstein 28

Landeskrankenhaus Hohenzollern 103

Landeskreditanstalt Hannover 30, 32

Landeskreditanstalt Württemberg 70

Landeskriminalpolizeiamt, preuBisches 139

Landeskulturwalter Berlin 313

Landeskulturwalter Süd-HannoverBraunschweig 313

Landeskundliche Forschungsstelle Hohenzollem 97

Landesleiter für Schrifnum Süd-HannoverBraunschweig 32
Landesleitung Berlin der Reichskammer der bildenden Künste 313

Landesleitung Berlin der Reichsmusikkam. mer 313

Landesleitung Berlin der Reichsschriftumskammer. Gruppe Buchhandel 314

Landesleitung Berlin der Reichstheaterkammer 310

Landesleitung Hessen-Nassau der Reichsmusikkammer 313

Landesleitung Westfaien-Nord der Reichskammer der bildenden Künste 313

Landesleitung Württemberg der Reichskammer der bildenden Künste 314

Landesleitung Württemberg der Reichsmusikkammer 313

Landesmedizinalkollegium. braunschw. 168

Landesmuseen für Kunst- und Kulturgeschichte, für Naturkunde und für Vor- und Frühgeschichle. westfal. 34

Landesmuseum

- Bonn 36

- Hannover 32

- Kassel 338

- Trier 36

Landesplanungsgemeinschaft

- Baden 352

- Kumessen 88

- Oldenburg-Bremen 354

- Rhein-Main 18, 352

- Westfalen 352

Landespolizei Lippe 20

Landespolizeiamt, hess. 17

Landespolizeigruppen Koblenz. Mannheim und München 134

Landespolizeiinspektionen Bayern. Süd und Südwest 134

Landespolizeikommando Augsburg 134

Landesprüfungsausschüsse der Reichsmusikkammer 310

Landesregierung Hessen 16

Landesregierung Lippe 11, 19

Landesregierung Schaumburg-Lippe 21

Landesrentenbank, preuBische 347

Landesschulamt für das höhere Schuiwesen. braunschw. 279

Landessiedlungsleitung West der NSKOV 518

Landessippenamt Oberthein 336

Landessippenamt Schleswig-Holstein 75

Landessparkasse Oldenburg 334

Landesstatistisches Amt, hess. 394

Landesstelle für Kautschuk und Asbest. bayer. 396

Landesstelle für Leder, bayer. 396

Landesstelle für Textilwirtschaft, bayer. 396 
Landesstelle für verschiedene Waren, bayer. 396

Landestheater

- Braunschweig 271

- Darmsladi 320

- Linz 463

- Westmark 76. 89

-. Rheinisches 36

Landesverband bayerischer Referendare 519

Landesversicherungsanstalt

- Berlin 253

- Hessen 253

- Hohenzollern 253

- Westralen 35

- Würuemberg 254

Landesverwaltungsgericht Hamburg 246

Landeswerkhaus (Arbeitshaus) Moringen 129

Landeswintschaftsamt

- Baden 332

- Berlin 102

- Bremen/Weser-Ems 395

- Fürh 395

- Hamburg 395

- Kiel 395

- München 396

- Saarbruicken/Westmark 395

- Stuttgar 396

Landgericht

- Aachen 206, 216

- Altona 202, 216

- Amberg 207, 216

- Ansbach 207. 216

- Amsberg 207, 216, 231

- Aschaffenburg 207, 216

- Augsburg 207. 216

- Aurich 207. 217

- Bamberg 207

- Bartenstein 195

- Bayreuth 207

- Berlin 206, 217, 316

- Bielefeld 207, 217

- Bochum 207, 217

- Bonn 208, 217

- Braunschweig 208. 230

- Bremen 208, 217

- Bückeburg 208. 217

- Coburg 206

- Darmstadt 206, 218

- Deggendorf 208, 218

- Detmold 19. 208, 218

- Dortmund 208, 218

- Düsseldorf 208, 218

- Duisburg 206, 218

- Eichstät 209, 218

- Ellwangen 209

- Essen 209, 218, 257

- Flensburg 209, 219
Landgericht (Forts.)

- Frankenthal 209. 219

- Frankfur 209, 219

- Freiburg 205. 210, 219. 231

- Gieben 206

- Göttingen 210, 219

- Hagen 210. 219

- Hamburg 210

- Hanau 206, 219

- Hannover 210, 220

- Hechingen 210. 220

- Heidelberg 205. 210. 220

- Heilbronn 206

- Hildesheim 210, 220

- Hof 210. 220

- Insterburg 195

- Itzehoe 211. 220

- Kaiserslautern 211. 220

- Karlsruhe 205. 211, 220

- Kassel 206, 220

- Kempien 211. 221

- Kiel 202, 211. 221

- Kleve 206, 221

- Koblenz 211. 221

- Köln 130, 148, 211, 221

- Konstanz 205. 211. 221

- Krefeld 212, 221

- Landau 212. 222

- Landshut 222

- Limburg 212. 222

- Lübeck 212, 222

- Lüneburg 206, 222

- Lyck 195

- Mainz 206

- Mannheim 205. 212. 222

- Marburg 212. 222

- Memmingen 206. 222

- Mönchengladbach 212. 223

- Mosbach 205, 206

- München I und II 212, 223

- Münster 206. 223

- Nürnberg-Fürth 206, 223

- Offenburg 205, 213. 223

- Oldenburg 185. 213.223, 233

- Osnabrïjk 213. 224

- Paderborn 213. 224

- Passau 213, 224

- Ravensburg 213

- Regensburg 213. 224

- Rottweil 213, 224

- Saarbrücken 214

- Schweinfurt 214

- Siegen 206

- Stade 214, 224

- Stuttgart 214, 224

- Traunstein 214, 224

- Trier 214, 225, 232 
Landgericht (Forts.)

- Tübingen 214, 225

- Ulm 214, 225

- Verden 214, 225

- Waldshut 205, 206, 225

- Weiden 214, 225

- Wiesbaden 215, 226

- Würzburg 206. 226

- Wuppertal 215, 226

- Zweibrücken 216, 226

Landratsamt

- Aachen 140

- Ahaus 95, 149

- Aichach 105, 149

- Alfeld 75, 87, 145

- Alsfeld 111

- Altötring 105

- Alzey 111

- Amberg 106

- Ammerland (Westerstede) 111. 152

- Ansbach 108, 150

- Aschaffenburg 109, 152

- Aurich 83

- Bad Aibling 105, 149

- Bad Brückenau 109

- Bad Gandersheim 111, 142

- Bad Kissingen 152

- Bad Mergentheim 151

- Bad Tölx 105, 149

- Bamberg 109

- Bayreuth 109

- Beckum 95, 149

- Beilngries 106, 151

- Bensheim 1 II

- Berchtesgaden 105, 149, 159

- Bergheim/Erf 148

- Bergreichenstein 105

- Bergstrabe 111, 155

- Bernkastel 100

- Bersenbrück 96

- Biberach 112, 156

- Bielefeld 94, 141

- Birkenfeld 89

- Blankenburg 111

- Bogen 107

- Bonn 90

- Braunschweig 111, 142

- Bretten 112, 146, 156

- Brilon 149

- Bruchsal 112, 146

- Brückenau 152

- Büdingen 111

- Bühl 112, 146

- Büren 94

- Calw 112, 151

- Celle 75

- Cham 150
Landratsamt (Fons.)

- Clausthal-Zellerfeld 87, 145, 155

- Cochem 89

- Coesfeld 95

- Dachau 105

- Dannenberg 92. 148

- Dieburg 111, 155

- Dillkreis 102

- Dingolfing 107. 151

- Dinkelsbuihl 108

- Dithmarschen 75

- Düren 140

- Ebermannstadt 109

- Ebern 109

- Ebersberg 105, 149

- Eggenfelden 107, 151

- Ehingen 112. 156

- Eichstāa 108

- Emmendingen 112, 146

- Ennepe-Ruhr-Kreis 81

- Erbach 111

- Erding 105, 149

- Erlangen 108, 150

- Eschenbach 106

- Eschwege 88, 147

- Esslingen 112, 151

- Euskirchen 148, 156

- Fallingbostel 92, 148

- Feuchtwangen 108

- Forchheim 109, 150

- Frankenberg 88, 147

- Frankenthal 110, 150

- Freising 105

- Freudenstadt 112

- Fnedberg/Bayern 149

- Friedberg 105, 111

- Friesland (Jever) 111

- Fritzlar-Homberg 88, 147. 156

- Fürstenfeldbruck 105

- Fürth 108, 150

- Füssen 110, 141

- Fulda 88, 147

- Garmisch-Partenkirchen 105, 149

- Gelnhausen 88, 102, 147, 156

- Gemünden/Main 109

- Germersheim 110

- Gerolzhofen 109

- Grafenau 150

- Grafschaft Bentheim 96, 150, 422

- Grafschaft Wittgenstein 143

- Griesbach 107

- GroB-Gerau 111

- Günzburg 110, 141

- Gunzenhausen 108, 150, 156

- Hammelburg 109, 152

- Hanau 88

- HaBfur 109 
Landratsamt (Forts.)

- Heidelberg 112. 146

- Heilbronn 112, 151, 156

- Helmstedt 111. 142

- Herford 141

- Hersbruck 108. 150

- Hersfeld 88, 146. 147

- Hilpoltstein 108. 150

- Höxter 94

- Hof 109

- Hofgeismar 88. 147

- Holzminden 111

- Hort 112

- Hünfeld 88, 147

- Ingolstadt 105

- Jever 152

- Karlsruhe 112, 146, 156

- Kehl 112, 146

- Kelheim 107

- Kempen-Krefeld 144, 156

- Kirchheimbolanden 110, 150

- Koblenz 89

- Köln-Land 148

- Königshofen 109, 152

- Konstanz 146, 156

- Kreuznach 89

- Krumbach 110

- Künzelsau 112, 151, 156

- Kusel 110.150

- Lahr 112. 146, 156

- Landsberg 105

- Landshut 107. 150

- Lauf 108, 150, 156

- Laufen 105

- Laupheim 151. 156

- Lauterbach 111

- Leer 83

- Leonberg 112, 151

- Lippstadt 143

- Lörrach 112, 146, 156

- Lohr 109

- Ludwigsburg 112, 151, 156

- Lübbecke 94, 141

- Lüdinghausen 95

- Main-Taunus-Kreis 101

- Mainz 111

- Mallersdorf 107

- Marburg/-Lahn 88, 146, 147. 156

- Markt Eisenstein 105

- Marktheidenfeld 109, 152

- Mayen 89

- Melle 96

- Mellichstadt 109, 152

- Memmingen 110, 141

- Meppen 96

- Meschede 81

- Miesbach 105. 149
Landratsamt (Forts.)

- Mindelheim 110.141

- Minden 94, 141

- Moers 84. 144

- Monschau 79.140.155

- Mosbach 112, 146. 156

- Mühldorf 105. 149

- Müllheim 112. 146. 156

- Münchberg 109

- München 105. 149

- Nagold 151

- Neuburg/Donau 110, 141

- Neuenbürg 151, 156

- Neumarkt 106

- Neunburg vorm Waild 106

- Neustadi am Rübenberg 86, 145

- NeustadVAisch 108

- NeustadVSchwarzwald 112, 146. 156

- Neustadi/Weinstraße 110, 150

- Neuwied 89

- Nördlingen 110, 141

- Norden 82

- Oberbergischer Kreis (Gummersbach) 90. 148

- Oberlahnkreis (Limburg) 101. 102. 145

- Obernburg 109. 152

- Oberviechtach 106

- Öhringen !12,151

- Offenburg 112,146, 156

- Parsberg 106. 151

- Passau 107, 150

- Pegniz 109, 150

- Pfaffenhofen 105

- Pfarkirchen 107. 150

- Prachatitz 105

- Rastatt 146

- Ravensburg 112, 156

- Regen 15I

- Regensburg 106. 150

- Rehau 109

- Reutlingen 112. 151

- Rheingaukreis 160

- Rheinisch-Bergischer Kreis (Mülheim/Rhein bzw. Bergisch Gladbach)

- Riedenburg 106

- Rockenhausen 110, 150

- Rosenheim 105. 164

- Rotenburg/Wümme 99

- Rothenburg ob d. T. 108

- Saarbricken 111

- Scheinfeld 108

- Schlüchtern 88, 102, 147

- Schongau 105

- Schotien 111

- Schrobenhausen 105

- Schwabach 108

- Schwalbach 145 
Landratsamt (Forts.)

- Schwelm 81

- Siegen 81, 143

- Siegkreis (Siegburg) 90. 148

- Simmern 89

- Sinsheim 112,146, 156

- Speyer 110

- Springe 86, 145, 155

- St Goarshausen 160

- St Ingber 111

- St. Wendel 111

- Staffelstein 109

- Stamberg 105

- Steinfur 95. 149

- Straubing 151

- Tauberbischofsheim 112, 146

- Tecklenburg 95, 143, 149

- Tirschenreuth 106

- Traunstein 105

- Trier 100

- Tübingen 112, 151

- Tutulingen 112, 156

- Überlingen 113, 146

- Uffenheim 108, 150, 156

- Unna 143

- Untertaunuskreis 101

- Usingen 102

- Vaihingen/Enz 112, 151

- Viechtach 150

- Viersen 155

- Villingen 113,146, 156

- Vilshofen 107

- VohenstrauB 106

- Wadern (Restkreis) 100

- Waiblingen 112, 151

- Waldshut 113, 146, 156

- Wangen 112, 151

- Warburg 94, 141

- Wasserburg 105, 149

- Wegscheid 151

- Weilburg 145

- Weilheim 105. 149

- WeiBenburg 108, 150

- Wertheim 112, 146

- Wesermarsch (Brake) 111, 152

- Wetzlar 102

- Wiesloch 112, 146, 156

- Wittlage 96, 150

- Wittlich 100

- Wittmund 83

- Witzenhausen 88, 147

- Wolfenbüttel 111, 142

- Wolfhagen 88, 147, 156

- Wolfratshausen 105, 156

- Wunsiedel 109

- Ziegenhain 88, 147

Landtag, bayer. 330,485
Landwirtschaftliche Hochschule Hohenheim 304

Landwirtschaftskammer Hessen-Nassau 399

Landwirtschaftsministerium. preuB. 391

Lateinamerikanischer Verein 173

Lebensborn e. V. 116, 207, 434

Lehr- und Forschungsgemeinschaft .Das Ahnenerte* 64, 73, 115, 270, 276, 294

Lehrerbildungsanstalt

- Alfeld 278

- Ankum 278

- Aurich 278

- Bad Driburg 278

- Bardel 278

- Bederkesa 278

- Braunschweig 307

- Celle 278

- Cloppenburg 270

- Dortmund-Lütgendorumund 278

- Dreihengen 270

- Friedberg/Hessen 307

- Göhrde 278

- Grobkrotzenburg 308

- Haigerloch 98.307

- Handrup 278

- Hannover 278

- Hofheim 308

- Holzwickede 278

- Kaiserslautern 307

- Königstein (Taunus) 308

- Lerbeck 278

- Loga 278

- Lüneburg 278

- Olpe 278

- Otweiler 307

- Paderborn 278

- Petershagen 278

- Stade 278

- Uchte 278

- Vechia 270

- Verden 278

Lehrregiment Kurfürst 430

Leitender Medizinalbeamter SchleswigHolstein 28

Leitender Medizinalbeamter Westfalen 34

Liga für Menschenrechte 122

Lotteriegemeinschaft, Hessisch-thüringische 18

Ludwig-Maximilians-Universität s. Universität München

Lügenabwehrstelle Süd-HannoverBraunschweig 487

Luftfahrtforschungsanstait München 339

Luftflottenkommando Reich $\mathbf{4 4 3}$

Luftgaukommando

- III 450

- V 450 
Luftgaukommando (Forts.)

- VI 236. 450

- VII 236, 450

- XI 236, 451

- XII 451

- XIL/XIII 236

- XIV 236. 237. 451

Lufigaupathologe VI 296

Luftschutzabteilungen (mot) Nr. 23, 34, 40 und $48 \mathbf{4 5 2}$

Luftschutzregiment $\mathrm{Nr} .7452$

Lufiwaffen-Bauregimenter VII und XII 452

Lufiwaffen-Durchgangsiager (Dulag) Oberursel 448

Luftwaffen-Oberbaustab Schleswig 452

Luftwaffen-Oberkriegsgericht München 235

Luftwaffenfühungsstab 437

Luftwaffenpersonalamt 438

Luftwaffenverwaltungsamt 438

Luftzeuggruppen 3, 6, 7, 11, 12 und See 452

Marine-Bereichskommandanten Eckernförde und Schleswig 236

Marine-Etappe Yokohama 440

Marine-Hauptfilm- und Bildstelle 436

Marinechefrichter Ostsee $\mathbf{4 5 3}$

Marinegruppenkommandos Ost und West 443

Marineintendantur Ost 453

Marinekommandoamt 436

Marinenachrichtendienst 436

Marineoberkommandos Ost und Nord 453

Marinepersonalamt 436

Marinestationen der Nordsee und der Ostsee 236. 453

Marineverbindungsstab Agram 440

Marineverwaltungsamt 436

Mars-Film GmbH 429. 439

Materialprïfungsamt Aachen 300

Materialprüfungsamt Berlin 301

Medizinalkollegium, Hamburg 168

Medizinaluntersuchungsstelle Bad Deynhausen 19

Medizinische Akademie Düsseldorf 36, 267

Messeamt Leiprig 262

Messerschmitt-Flugzeugwerke 437, 447

Metropol-Theater 338

MIAG (Mühlenbau- und Industrie AG) 343

Milchwirtschaftsverband Hessen-Nassau 399

Militärbefehlshaber

- Belgien und Nordfrankreich 56

- Frankreich 55, 64

- Griechenland 56

- Serbien 56

- Saloniki-Ägäis 56

Militärdepartement, oldenburg. 67

Mineralöl-Baugesellschaft mbH. 384
Ministerialabteilung für Bezirks- und Körperschaftsverwaltung. wüntemberg. 11!

Ministerialabteilung für die Fachschulen. württemberg. 279

Ministerialabteilung für die höheren Schulen. würtemberg. 278

Ministerialabteilung für die Volksschulen. württemberg. 279

Ministerium der Auswärtigen Angelegenheiten. bayer. 13

Ministerium der Auswärtigen Angelegenheiten, württemberg. 402

Ministerium für auswärige Angelegenheiten. oldenburg. 18

Ministerrat für die Reichsverteidigung 2. 13. 66

Mitteldeutscher Arbeitgeberverband öffentlicher Verwaltungen und Betriebe. Magdeburg 76

Mittelmeer-Handels- und Industrie GmbH 371

Mittelmeer-Reederei 371

Mittelstelle deutscher Bauernhof 103

Montan-Industriewerke $\mathrm{GmbH} 364$

Motorbrigade des NSKK

- Bayerische Ostmark 496

- Franken 496

- Kurpfalz-Saar 496, 497

- Südwest 496

Motorgruppen des NSKK ..Adolf Hühnlein". Hessen. Hochland und Südwest 496

Motorobergruppe Süd 496

Motorsportschule Bayerische Ostmark. Bayreuth-Saas 109. 496

Motorstandarten des NSKK 46 (Hanau), 48 (Marburg), 49 (Frankfurt), 55 (Ludwigsburg), 62 (Bremen), 86 (München), 87 (Augsburg), 95. 148 (Wiesbaden), 152 (Trier), 155 (Heilbronn), 162, 163. 164. 181 (Bayerischer Wald), 187 (Kempten) 497

Münzmetalldepot des Reiches 326

Mullahschule Dresden der SS 117

Murgschifferschaft 333

Museumsgeselischaft Tübingen 299

Musikschule der Waffen-SS 271

Nachrichtensammelstelle des Reichsministeriums des Innern 59

Nachrichtenstelle der Polizeidirektion Bremen 142

Nachrichtenstelle des braunschweigischen Staatsministeriums 19

Nachrichtenstelle Lübeck 27

Nachtjagdgeschwader Nr. 1.6 und 11451

Nationaler Arteitsdienst "Rote Erde" 423 
Narionaler Kampfound der Sparer und Rentner 72

Nationaler Klub von 191957

Nationalkomitee Freies Deutschland 122. 317, 464

Nationalpolitische Erziehungsanstalt

- Am Steinhuder Meer 85

- Backnang 278, 279

- Bensberg 279

- Berlin-Spandau 279

- Haselünne 75

- Iffeld 162, 279

- Oranienstein 162, 279

- Plōn 279

- Potsdam 165

- Rottweil 278, 279

Nationalpolnische Bewegung 33

Nationalsocialistische Beweging (NSB) 474

Nationalsozialistische Frauenschaft 423, 461. 462, 487, 501

Nationalsozialistische Freiheitsbewegung 487

Nationalsozialistische Kriegsopferversorgung (NSKOV) 15, 113, 517

Nationalsozialistische Schwesternschaft 85 , 106, 294, 296, 502, 515, 516, 517

Nationalsozialistische Volkswohlfaht (NSV) 14, 15, 22, 25, 31, 73, 76, 77, 81, 158 . $315,333,353,460,462,463,484,489$, 502, 515

Nationalsozialistischer Deutscher Ärztebund 167, 518

Nationalsozialistischer Deutscher Dozentenbund (NSD.-Dozentenbund) und NSDozentenschaft 283, 289, 291, 292, 294. 298, 300, 304, 467, 505. 506. 507, 508. 521

Nationalsozialistischer Deutscher Studentenbund (NSDStB) 25, 269, 271, 281, 283. 287, 292, 294, 461, 462, 503-507

Nationalsozialistischer Lehrerbund (NSLB) $81,255,271,287,295,487,507,520-522$

Nationalsozialistischer Rechtswahre bund (NSRB) 33, 286, 289, 295, 518

Nationalsozialistischer Reichsbund für Leibesübungen (NSRLB) 71, 270, 318, 508

Nationalsozialistisches Fliegerkorps (NSFK) 497

Nationalsozialistisches Kraftfahr-Korps (NSKK) 450, 461, 462. 463. 480. 496, 507

Nationaltheater München 320

Neu Beginnen 123

Neue Heimat, Bau- und Wohnungsgesellschaft 334, 511

Neuguinea-Kompagnie 43

Neunkirchner Eisenwerke 352

Niedersachsenorchester 30
Niedersächsische Landesbühne 30, 32

Niedersächsische Landesstelle für Familienkunde 75

Niedersächsischer Heimatbund 286

Nord- und Ostdeutsche Forschungsgemeinschaft 178

Norddeich-Radio 405

Norddeutsche Rundfunk A.G. NORAG 30

Norddeutscher Lloyd 393

Nordische Geselischaft 27. 270, 466

Nordland-Verlag 116, 121

Nordseepädagocicum Südstrand 277

Nordwestdeutsche Arbeitsgemeinschaft fur Wohlfahrtspflege 74

Notgemeinschaft der Deutschen Wissenschaft 61. 272. 281. 296. 306

Notwerk der Deutschen Jugend 89. 424

NS-Altherrenbund 294. 503. 505. 506

NS-Auteitsgauverein Baden 424

NS-Bauverein 73

NS-Betriebszelle am Staatstheater Karlsruhe 320

NS-Betriebszellenorganisation (NSBO) 487. $509,511,513,514$

NS-Bund Deutscher Technik 363, 372. 523

NS-Führungsstab der Wehrmacht 431. 467

NS-Gau-Oberschule am Donnersberg 110

NS-Gemeinschaft ,Kraft durch Freude“

(KdF) 2, 46, 91, 93, 122, 184, 319, 320.

321. 349. 358. 394. 488. 508. 511, 512.

$513,514,515$

NS-Hago 511,512

NS-Kulturgemeinde 34, 97, 271, 310, 314. 320, 321. 466, 468, 513

NS-Oberschule Feldafing 463

NSD.-Dozentenbund Süd-Hannover-

Braunschweig 505

NSD.-Dozentenbundakademie Kiel 508

NSD.-Dozentenbundsführungen Köln. Marburg und Tübingen 508

NSDAP (vor allem Mitgliedschaft, insbes. Unterbringung im offentlichen Dienst. Finanzienung. Verhäl(nis zum Staat) 4, 5 . $9,11,12,13,14,15,16,17,18,19,22$. $23,24,26,27,28,29,34,35,36,38,44$. $45,54,57,59,63,66,67,68,69,70,73$. $74,76,77,78,80,82,83,85,87,90,92$. $95,97,102,105,106,107,109,111,112$. $113,119,148,151,157,158,167,179$. 180. 183, 184, 185, 200, 201, 204, 205. 208. 209. 210, 212, 215, 216, 220, 226. 247. 255, 262, 265, 269, 270, 271, 282. $287,288,289,291,292,295,296,304$, $316,320,330,331,333,334,339,341$. $342,343,350,353,374,396,400,405$. $414,416,417,420,422,425,430,435$. $442,444,445,449,450,452,456-523$ 
NSFK-Gruppen 15 (Wüntemberg-

Hohenzollern) und 16 (StraBburg). -Standarten 80 (Karisruhe). 82. 96 (Augsburg), 102 (Heilbronn) und 103 (Kirchheim) 496

NSKK-Trarsporteinheiten s. Transporteinheiten TodUSpeer

NSLB s. Nationalsozialistischer Lehrerbund NSV s. Nationalsozialistische Volkswohlfahrt

Oberbauleitungen Ems, Hannover. Pirmasens. Saarbricken und Schwaben der OT 364

Oberbefehlshaber West 435

Oberbergamt

- Bonn 357, 394

- Clausthal-Zellerfeld 357

- Dortmund 357, 394

- Karisruhe 357

- München 357, 394

- Saarbricken 357. 394

Oberberghauptmann 357

Oberberufungskommission für die Gewerbesteuerveranlagung 344

Oberes Amt Volksgesundheit, Rassenpolitik und Sippenkunde 460

Oberfinanzkasse Berlin 340

Oberfischmeister für die Provinz Hannover 96

Oberförsterei des Chefs der Zivilverwaltung für den Bezirk Bialystok 338

Oberforstdirektion Hessen 18

Oberforstdirektionen Bayreuth. München und Regensburg 395

Oberkommando der 6. Armee 435

Oberkommando der Kriegsmarine (OKM) 235. 436, 439

Oberkommando der Luftwaffe 437

Oberkommando der Wehrmacht (OKW) 42 . 272, 362, 428, 433

Oberkommando des Heeres (OKH) 42, 272. 274. 349, 432, 433, 439

Oberkommandos der 1., 2., 4., 5.. 6.. 7.. 12. und 18. Armee 442

Oberkommandos der Heeresgruppen 1, 2, 6. $A, B, C, D, G$ und $H 441$

Oberkriegsgericht der Flotte 235

Oberlandesgericht

- Bamberg 200, 203

- Berlin s. Kammergericht

- Braunschweig 200, 203

- Breslau 194

- Celle 200, 203. 204

- Darmstadt 200, 204

- Düsseldorf 201, 204

- Frankfur 201, 205

- Hamburg. (Hanseatisches) 198. 201. 204

- Hamm 197. 201. 204
Oberlandesgericht (Forts.)

- Karisruhe 201, 205

- Kassel 197. 201

- Kiel 194. 202. 205

- Köln 202. 204. 205

- München 14. 202. 205. 519

- Nürnberg 202. 206

- Oldenburg 199. 206

- Stuttgart 199

- Zweibrücken 202. 206

Oberpräsidium

- Hannover 29.67.85

- Hessen-Nassau 35

- Rheinprovinz 35

- Schleswig-Holstein 27, 137, 147

- Westfalen 32,66, 442

Oberprisenhof 45,249

Oberpriffstelle für Schund- und Schmutzschriften, Leipzig 308

Oberrechnungskammer Hessen 339

Oberreichsanwaltschaft beim Reichsgericht 182. 199

Oberreichsanwaltschaft beim Volksgerichtshof 182, 194. 199. 221. 226

Oberschulbehörde. Hamburg 25

Oberseeamt 37i

Oberste Baubehörde, bayer. 69

Oberste Bauleitung für Elektrifizierungen 387

Oberste Bauleitungen der Reichsautobahnen 389, 403

Oberste Behörden für die Prüfung von Kaltblutpferden und für Vollblutzucht und -rennen 386

Oberste Kommissare für die Operationszonen Adriatisches Küstenland und Alpenvorland 55

Oberste SA-Führung (OSAF) 104. 491, 494. 495

Oberste Spruchstelle für Umlegungen und für Wasser- und Bodenverbände 243

Oberster Ehren- und Disziplinarhof der DAF 512

Oberster Gerichtshof für das Saargebiet 202

Oberster Prüfungshof für Volkszugehörigkeitsfragen 119.173

Oberster Rechnungshof, bayer. 339

Oberstes FideikommiBgericht 239

Oberstes Gericht für die Sondergerichtsbarkeit der SS und Polizei 237

Oberstes Landesgericht. Bayerisches 195. 202

Oberstes Parteigericht 471

Oberversicherungsamt

- Augsburg 253

- Aurich 418

- Bertin 253. 419

- Darmstadt 253 
Oberversicherungsamt (Forts.)

- Detmold 253. 419

- Konstanz 253

- Lüneburg 419

- Minden 419

- Reudingen 253

- Sigmaringen 253. 419

- Stuttgan 254

Oberverwaltungsgericht, lipp. 245

Oberverwaltungsgericht. preuB. 245. 247. 254,256

Offizierswitwen- und -waisenkasse. hessische 18

OKW-Fihrungsstab Nord 6

Opel A.G. Rüsselsheim 158, 514

- Adam-Opel-Gedächtnisstiftung 187

Opferning der NSDAP 478

Ordensburg Falkenburg am Crössinsee 475

Ordensburg Sonthofen 475

Ordensburg Vogelsang 352, 475

Organisation Escherich 474

Organisation Todt (OT) 153. 189. 332, 333. 363. 364, 412, 418, 514

Organisationsleitung der Reichspaneitage 461

Ortsmusikerschaft Limburg/Lahn 313

Ostbahn 370

Osteuropa-Institut Breslau 178

Ostfriesische Landes-Volksbücherei 104

Ostfriesische Landschaft 30, 103

Ostfriesische Ritterschaft 104

Ostindustrie GmbH 121

Ostland-Institut Danzig 178

Pädagogisches Institut Hamburg 25

Pareiamiliche Prüfungskommission zum Schutze des NS-Schriftums 291, 295, 471

Parteikanzlei 228, 326, 428, 456, 457, 458. 461, 463, 466, 467, 470, 478, 486

Parteimuseum Niedersachsen e. V. der NSDAP 487

Patentanwaltskammer 188

Paul-Nipkow-Sender 316

PEN-Club 310

Persönlicher Stab Reichsführer SS 114-116

Personal- und Organisationsamt Westmark 10

Personalamt der SS 117

Personalamt Hessen 16

Personalhauptamt der SS 119. 126

Philipps-Universität s. Universität Marburg

Philosophisch-theologische Hochschule

- Bamberg 109, 267

- Dillingen (Donau) 267, 305

- Eichstät 267

- Freising 267, 305

- Passau 267

- Regensburg 267

Phönix-Verlag 465
Physikalisch-Technische Reichsanstalt 61. 273, 337

Pionierbataillone Nr. 7 und 47450

Planungsstelle für Gesundheitsbedarf 61

Politischer Polizeikommandeur der Länder 121. 138

Politisches Archiv des Auswärigen Amtes vor 194539

Polizei-Bataillon II im Wehrkreis V 135

Polizei-Bataillone Nr. 51, 63, 91, 93, 101. 105, 121, 122, 124, 307, 309135

Polizei-Bataillone Nr. 63 und 65137

Polizei-Regimenter 3, 14 und 15135

Polizei-Standortbataillon Köln 135

Polizeiamt .Reichswerke Hermann Göring . Watenstedt-Salzgitter 142

Polizeiamt Herford 141

Polizeibehörde Hamburg 24

Polizeidirektion Braunschweig 142

Polizeidirektion Nürnberg-Fürth 149. 150

Polizeidisziplinarkammer Hamburg 256

Polizeigefangnis Hamburg-Fuhlsbüttel 129

Polizeihaftlager Hinzer 132

Polizeikasse. hess. 18

Polizeioffizierschule Fürstenfeldbruck 135

Polizeipräsidium

- Aachen 78

- Berlin 474

- Duisburg 155

- Frankfurt 145

- Hamburg 342

- Hannover 145

- Kassel 147

- Kiel 28

- Mainz 150

- München 149

- Saarbrïcken 138. 155

Polizeischule Fürstenfeldbruck 134

Polizeischule Hannoversch Münden 87

Porzellanmanufaktur Allach 121

Präsidialkanzlei des Führers und Reichskanzlers 1, 4, 336. 457

Präsidialrał der Reichsschriftumskammer 311

Preisbildungs- und Preisüberwachungsstelle Bremen 393

Preisbildungsstelle Bückeburg 360, 412

Preisbildungsstelle Kiel 28

Preisprüfungsstelle Arnsberg 359

Preisprüfungsstelle Kiel 395

Preisüberwachungsstelle Detmold 20

Preisüberwachungsstelle Stuttgart 360

Presse- und Propagandaamt der Reichsjugendführung 498

Pressegerichtshof 257

Pressekonferenz der Reichsregierung 263

Prisenhof Berlin 249

Prisenhof Hamburg 249 
Privalkanzlei Adolf Hitler 457

ProduktionshauptausschuB Lederwirtschaft 363

Propaganda-AusschuB für die Olympischen Spiele 308

ProvinzialausschuB Westfalen 32, 34, 93

Provinzialbeauftragter für Naturschutz, thein 36

Provinzialbibliothek Hannover 29, 32

Provinzialdienststelle Rheinprovinz und Hobenzollern des Deutschen Gemeindetages 76

Provinzialemährungsamt Berlin 102

Provinzialfeuerwehrschule Celle 32

Provinzialinstitut für psychiatrischneurologische Erbforschung 169

Provinzialinstitut für westfälische Landesund Volkskunde 34

Provinziallebensversicherungsanstalt Schleswig-Holstein 28

Provinzialrat

- Hannover 29, 32

- Rheinprovinz 36

- Schleswig-Holstein 28

- Westfalen 32, 34

Provinzialschulkollegium

- fuir die Rheinprovinz 278

- für Hannover 29, 278

- für Schleswig-Holstein 277

- für Westfalen 278

Provinzialstelle für Bevölkerungs- und Rassenkunde Hannover 286

Provinzialstelle für Niedersächsische Familienkunde 32

Provinzialversicherungsanstalt Hannover 32

Provinzialversicherungsanstalt Rheinland 36

Provinzialverwaltung

- Hannover 32, 75, 245

- Hessen-Nassaul 35

- Rheinprovinz 36

- Schleswig-Holstein 28, 352

- Westfalen 34, 80

Prüfstelle für den Bereich der Organisation der gewerblichen Wirtschaft 380

Prüfstelle für Schund- und Schmutzschriften, Berlin 308

Prüfungsamt fur Diplomchemiker Münster 297

Prüfungsstelle Bekleidungsindustrie 383

Pruifungsstelle Bergbau 383

Prifungsstelle Eisenschaffende Industrie 383

Prüfungsstelle Feinmechanik und Optik 383

Prüfungsstelle Frachten 383

Prüfungsstelle GieBereiindustrie 383

Prüfungsstelle Glasindustrie 383

Prüfungsstelle Holzverarbeitende Industrie 383
Prüfungsstelle Keramische Industrie 383

Prüfungsstelle Lederindustrie 383

Prüfungsstelle Maschinenbau 383

Prüfungsstellen für den AuBenhandel 380

Publikationsstelle Berlin-Dahlem 12, 112. 177

Quartiermeistergnuppe z.b.V. des Generalkommandos XII 445

RAD-Gruppen 257 und 280424

Radio Monte Carlo 317

Radio Mundial 48

Rasse- und Siedlungshauptamt (RuSHA) der SS 119, 174

Rassenamt der SS 119

Rassenbiologische Forschungsstelle 166

Rassenbiologisches Institut 282

Rassenpolitisches Amt der NSDAP 470

Rat der Ev.-luth. Kirche in Deutschland 144

Realschule Apenrade 277

Rechnungsami Baden 339

Rechnungshof Baden 338

Rechnungshof des Deutschen Reiches 4, 64 , 325, 335, 337

Rechnungshof Hamburg 339

Rechnungshof Württemberg 339

Rechtsberatungsstelle Medebach des NSRB 519

Redaktion .Der Stürmer" 146.48]

Redaktion der .Jomsburg" 178

Redaktion für Wissenschaft und Hochschule des DNB 318

Regierender Bürgermeister Bremen 458

Regienung des Generalgouvernements 55

Regienungen, Regierungspräsidenten s. Bezirksregierung

Regierungskommission für das Saargebiet 7. 9

Regierungspräsident der Reichshauptstadt 102

Regierungswirtschaftsamt für Unterfranken 395

Reichs-Kredit-Gesellschaft 327

Reichsabteilung für weibliche Erziehung im NSLB 522

Reichsadoptionsstelle der NSV 515

Reichsärztekammer 167, 289

Reichsakademie für Leibesübungen 63

Reichsamt Freiwillige Feuerwehren 126

Reichsamt für Agrarpolitik 15. 469

Reichsamt für Bodenforschung 378

Reichsamt für das Landvolk 469

Reichsamt für Landesaufnahme 4, 66

Reichsamt für wehrwirtschaftliche Planung 376

Reichsamt für Wenterdienst 439

Reichsamt für Wirschaftsausbau 377

Reichsamt Technische Nothilfe 126 
Reichsanstalt für Aubeitsvermittlung und Arbeitslosenversicherung(-fürsorge) 415

Reichsanstalt fuir Bild und Film in Wissenschaft und Unterricht 260, 277

Reichsanstalt für Erdbebenforschung 271

Reichsanstalt für Fischerei 386

Reichsanstalt für Getreideverarbeitung 385

Reichsanstalt für Holzforschung 385

Reichsanstalt für $\mathrm{MaB}$ und Gewich 273

Reichsanstalt für Tierseuchenbekämpfung 165

Reichsanstalt für Vitaminprüfung und Vitaminforschung 165

Reichsanstalt für Wasser- und Luftgüte 166

Reichsapothekerkammer 167

Reichsarbeitsdienst (RAD) 8, 14, 15, 19. $22,25,31,37,54,66,79,80,85,96$. $99,106,113,296,326,333,334,336$. $340,341,343,348,390,394,404,415$, $419-425,433,441,449$

Reichsarbeitsdienst für die weibliche Jugend $71,425,517$

Reichsarbeitsfïhrer 420

Reichsarbeitsgemeinschaft Erfindungswesen 523

Reichsarbeitsgemeinschaft für die Ausbildung von Volkswirten 305

Reichsarbeitsgemeinschaft für naturgemäßes Lebens- und Heilwesen 70

Reichsarbeitsgemeinschaft für Raumforschung 348

Reichsarbeitsgemeinschaft für Volksernährung 165

Reichsarbeitsgemeinschaft Heil- und Pflegeanstalten 166

Reichsarbeitsgemeinschaft Schadenverhütung e. V. 262, 315

Reichsarbeitsgericht 180,250, 251

Reichsarbeitskammer 407, 511,512

Reichsarbeitsministerium 336, 407, 410, 411. 413. 419, 511

Reichsarboretum 292

Reichsarchiv 4, 62

Reichsart SS und Polizei 114

Reichsaufsichtsamt für das Kreditwesen 378

Reichsaufsichtsamt für das Versicherungswesen 379

Reichsausbildungslager des $\mathrm{HJ}$ Streifendienstes, Freusburg 483

Reichsausführungsbehörde für Unfallversicherung 418

Reichsausgleichsstelle für öffentliche Aufuräge 384

ReichsausschuB der Kriegsbeschädigten- und Kriegshinterbliebenenfürsorge 410

ReichsausschuB für Fremdenverkehr 308

ReichsausschuB für Leistungssteigerung 375
Reichsausschuß für Volksgesundheitsdienst 167

ReichsausschuB für Volkswirtschaftliche Aufklärung 315

Reichsautobahnen-Direktion 372. 389

Reichsautozug Deutschland der Reichspropagandaleitung 464

Reichsbahn-Waisenhor 387

Rejchsbahnausbesserungswerke 402

Reichsbahnbaudirektion Berlin 351, 387

Reichsbahnbaudirektion München 387

Reichsbahndirektion

- Essen 397, 402

- Hamburg 402

- Hannover 402

- Karisruhe 402

- Köln 370. 402

- Saarbrücken 402

- Stutugart 402

- Wuppertal 403

Reichsbahnfilmstelle 372

Reichsbahnversicherungsanstalt 417, 418

Reichsbahnversuchsamt Berlin-Grunewald 388

Reichsbahnzentralamt Berlin 363, 387

Reichsbahnzentralamt für Sozial- und Personalwesen 388

Reichsbahnzentralamt München 388

Reichsbank 2, 4, 54. 327, 345

Reichsbankhauptstelle Frankfurt/Main 346

Reichsbanknebenstelle Rheydt 346

Reichsbankstelle Kaiserslautern 346

Reichsbanner Schwarz-rot-gold 27, 123, 220. 244

Reichsbauamt Ludwigsburg 340

Reichsbaudirektion 326

Reichsbauernführer 366

Reichsbauernral 367

Reichsbeauftragter für Chemie 378

Reichsbeauftragter für das Seefahrtsschulwesen 388

Reichsbeaufuragter für das Wahlprüfungsverfahren 62

Reichsbeauftragter für die Deutsche Filmwirtschaft 319

Reichsbeauftragter für die Heil- und Pflegeanstalten 166

Reichsbeauftragter für die Mode 262

Reichsbevollmächtigter für den totalen Kriegseinsatz 261, 362

Reichsbewegung Deutsche Christen 490

Reichsbund der Deutschen Beamten 85, 520

Reichsbund der Kinderreichen 470, 508

Reichsbund Deutsche Fanilie 485

Reichsbund deutsche Jägerschaft 387

Reichsbund für Volkstum und Heimat 36, 95. 271 
Reichsbund jüdischer Frontsoldaten 87

Reichsburg Cochem 200

Reichsdienststrafhof 254

Reichsdisziplinarhof 53, 254

Reichsdisziplinarkammern Bremen. Hamburg. Schieswig und Stuttgar 255

Reichsdozentenführung 456

Reichsdozentenwerk 288, 304

Reichsdramaturg 263

Reichsdruckerei 4, 387

Reichsehrengerichtshof 257

Reichsendeleitung 316

Reichserbhofgericht 181, 239

Reichsernährungsministerium 239, 261, 326. 336, 364, 391, 469

Reichserziehungsministerium 61, 259-261, 266, 271, 271, 273, 274, 278, 280, 281. 291, 292, 294, 298, 301, 303, 304. 305. 307, 325

Reichsfachgruppe Gas- und Wasserversorgungsberriebe 382

Reichsfalkenhof 392

Reichsfeststellungbehörde 244

Reichsfilmintendant 263, 318

Reichsfilmkammer 312,338

Reichsfinanzhof 4, 249

Reichsfinanzministerium 323-327, 346

Reichsfinanzschule Ilmenau 328

Reichsforschungsrat 272, 288, 290, 292, 295. 297, 302, 437

Reichsforstamt 368, 384

Reichsfrauenführung 456, 501

Reichsfremdenverkehrsverband 308

Reichsführer SS und Chef der Deutschen Polizei 22, 33, 113

Reichsführerinnenschule Polle 85

Reichsführerschule des NSDStB 504

Reichsgericht 180, 182, 198, 250, 252, 254

Reichsgesundheitsamt 61,165

Reichsgesundheitsführer 30,58

Reichsgruppe Banken 382

Reichsgruppe Energiewirtschaft 356, 382

Reichsgruppe Fremdenverkehr 356, 380

Reichsgruppe Handel 356, 381

Reichsgruppe Handwerk 356, 382

Reichsgruppe Industrie 356, 381, 511

Reichsgruppe Rechtsanwälte im NSRB 519

Reichsgruppe Verkehrswesen 356

Reichsgruppe Versicherungen 356, 380

Reichshauptkasse 327

Reichsheimstättenamt der DAF 102, 511

Reichsinnenministerium 16, 22, 57-62, 173 , $178,244,259,261,263,265,274,336$, 420, 473

Reichsinnungsvertand des deutschen Bildhaver- und Steinmetzhandwerks 382
Reichsinnungsverband des Kraftfahrzeughandwerks 382

Reichsinnungsverband des Uhrmacherhandwerks 382

Reichsinspektor für die Seeschiffer- und Seesteuermannsprüfung bzw. für die Schiffsingenieur- und Maschinistenprüfung 388

Reichsinstitut für ältere deutsche Geschichtskunde 274

Reichsinstitut für ausländische und koloniale Forstwirtschafi 384

Reichsinstitut für Berufsausbildung in Handel und Gewerbe 379

Reichsinstitut für Geschichte des neuen Deutschland 4, 274, 295

Reichsinstitu! Sven Hedin für Innerasienforschung 276

Reichsjägerhaus Hainberg 392

Reichsjägerhof Braunschweig 73, 334

Reichsjägerhof Riddagshausen 392

Reichsjägerhof Rominten 329

Reichsjägermeister 387

Reichsjagdamt 368

Reichsjagdmuseum 349

Reichsjugendführung 98.433,

Reichsjustizministerium 179, 183, 201, 227. 228, 229, 239

Reichsjustizprüfungsamt 188

Reichskammer der bildenden Künste 312. 313, 314, 408

Reichskammer der Technik 15, 331

Reichskammer der Winschaftstreuhänder 384

Reichskanalamt 403

Reichskanzlei 2-6, 261, 264, 325, 336, 349. 351,457

Reichsklub vom 30. Januar 1933310

Reichsknappschafi 416.417.418

Reichskolonialamt 42

Reichskolonialbund 77, 280, 304, 464, 469

Reichskolonialministerium 353, 469

Reichskolonialschule Witzenhausen 279, 286

Reichskommissar für Arbeitsbeschaffung 2. 410

Reichskommissar für Aus- und Einfuhrbewilligung 375

Reichskommissar für Bremen 26

Reichskommissar für das Ostland 55

Reichskommissar für das Sanitäts- und Gesundheitswesen 58, 165

Reichskommissar für den Arbeitsdienst 423

Reichskommissar für den gewerblichen Mittelstand 3, 376

Reichskommissar für den sozialen Wohnungsbau 70, 407

Reichskommissar für die Ablösung der Reichsanleihen alten Besitzes 327 
Reichskommissar für die Behandlung feindlichen Vermögens 187

Reichskommissar für die besetzten niederländischen Gebiete 55

Reichskommissar für die besetzten norwegischen Gebiete 55

Reichskommissar für die Festigung deutschen Volkswums 119, 173, 175

Reichskommissar für die Preisbildung 3. 358, 359, 360

Reichskommissar für die Rückgliederung des Saarlandes/für das Saarland 6, 9

Reichskommissar für die Saapfalz 9

Reichskommissar für die Seeschiffahr 369. 371

Reichskommissar für die Übergabe des Saargebietes 6

Reichskommissar für die Ukraine 55

Reichskommissar für Preisüberwachung 3. 359

Reichskommissar für Lübeck 27

Reichskommissare beim Oberprisenhof und beim Prisenhof Hamburg 249

Reichskriegerbund "Kyffhäuser" 5, 31

Reichskriegsgericht 235

Reichskriegsministerium 428, 429

Reichskriegsschädenamt 243

Reichskriminalpolizeiamt 121, 124

Reichskulturkammer 14, 26, 30, 63, 79. 80 . $91,99,108,262,309,332,356,390,479$

Reichskultursenat 310

Reichskuratorium für Technik in der Landwirtschaft 385

Reichslager für Beamte, Bad Tölz 409

Reichslastverteiler 382

Reichslehrgemeinschaft Partei- und Wehrmachtsschulung 467

Reichslehrweberei Langenbielau 509

Reichsleiter für die Presse 310, 465

Reichsleitung der NSDAP 64, 165, 202, 456, 456-471, 460, 462, 487

Reichslufufahrtministerium 302, 437, 491

Reichsluftschutzbund 31

Reichsministerium für Bewaffnung und $\mathrm{Mu}$ nition 326, 361

Reichsministerium für die besetzten Ostgebiete 55, 466

Reichsministerium für die kirchlichen Angelegenheiten 21, 265, 325

Reichsministerium für Rüstung und Kriegsproduktion $326,349,352,360,361-363$. 431, 437

Reichsmonopolamt 328

Reichsmonopolverwaltung für Branntwein 328

Reichsmotorsportschule Gandersheim 334

Reichsmütterdienst 86
Reichsmusikerschaft 310

Reichsmusikkammet 263, 310, 313, 320

Reichsnährstand 16, 20, 21, 89, 91, 295. $304,326,331,335,336,338,365,366$. 386. 392, 397, 399, 415

Reichsnotarkammer 188

Reichsobersecamt 248. 403

Reichsorganisationsleiter der NSDAP 456. 460. 485

Reichspatentamt 187, 257, 389

Reichspostdirektion

- Augsburg 404

- Berlin 404

- Braunschweig 404

- Bremen 405

- Dorumund 405

- Düsseldorf 405

- Frankfur/Main 405

- Hamburg 405

- Hannover 405

- Karisruhe 405

- Kiel 405

- Köln 406

- München 406

- Münster 406

- Nürnberg 406

- Oldenburg 406

Reichspostfilmstelle 375

Reichspostministerium 261, 373, 406

Reichspostmuseum 373

Reichspostzentralamt, Abteilung München 389

Reichspressechef der NSDAP 465

Reichspressekammer 310

Reichspropagandaamt

- Baden 309. 320

- Berlin 262

- Hessen-Nassau 309

- Moselland 309

- Schwaben 309

- Westmark 309

Reichspropagandaleitung der NSDAP 228. $264,445,462,463,475,521$

Reichspropagandaministerium 47, 176, 181, 228, 261-265, 275, 308, 309. 316, 318. $320,325,336,482$

Reichsprotektor in Böhmen und Mähren 55

Reichsprüfungsamt für das Lehramt an höheren Schulen 260

Reichsprüfungsamt für den höheren und gehobenen Verwaltungsdienst 65

Reichsprüfungsamt für den höheren vermessungstechnischen Verwaltungsdienst 63

Reichsrat 4, 58

Reichsrechtsamt der NSDAP 518

Reichsrechtsanwaltskammer 188 
Reichsring für nationalsozialistische Propaganda und Volksaufklärung 463

Reichsrundfunkgeselischaft 312,316.418

Reichsrundfunkkammer 312

Reichsschatzmeister der NSDAP 213, 456. 461

Reichsschiedsamt beim Reichsversicherungsamt 252

Reichsschiffsvermessungsamt 388

Reichsschleppbetrieb 403

Reichsschrifuumskammer 32, 311

Reichsschuldenverwaltung 327

Reichsschule der DAF für Ingenieure, Gelsenkirchen 511

Reichsschule der NSDAP Bernau/Chiemsee 485

Reichsschule der NSDAP Feldafing 475

Reichsschule des BDM 73

Reichsschule des Reichsnährstands Burg Neuhaus 366

Reichsschule I der NS-Frauenschaft Coburg 501

Reichsschule Potsdam des RAD 420

Reichsschule Potsdam-Babelsberg der Arbeitsverwaltung 415

Reichsschulungsburg Erwitte der NSDAP 475, 477, 490

Reichssegelfitegerschule Ith 334

Reichssender Frankfurt 17, 316

Reichssender Stuttgart 316, 317

Reichssicherheitsdienst 127, 463

Reichssicherheitshauptamt 45, 121-126, 160, 174. 264

Reichssippenamt 64, 376, 459

Reichssparkommissar 325, 335, 336

Reichssportamt 62

Reichssportführer 270

Reichsstatthalter

- Baden 8

- Bayern 8

- Braunschweig und Anhalt 8

- Hamburg 23, 24

- Hessen 8

- Lippe und Schaumburg-Lippe 10, 21, 360

- Lübeck 8

- Oldenburg und Bremen/Weser-Ems 8, 26, 67, 74, 255

- Preußen 8

- Westmark 9

- Württemberg 9.69

Reichsstatthaiter-Jakob Sprenger-Stiftung 17

Reichsstelle für Asteitsschutz 410

Reichsstelle für Arbeitsvermitulung 411

Reichsstelle für Baustatik 410

Reichsstelle für Bodenforschung 378, 431

Reichsstelle für Chemie 382
Reichsstelle für das Auswanderungswesen 176

Reichsstelle für den AuBenhandel 383

Reichsstelle für den Unterrichtsfilm 277

Reichsstelle für Devisenbewirtschaftung 344. 357

Reichsstelle für Edelmetalle 382

Reichsstelle für Eier 386

Reichsstelle für Eisen und Metalle 382

Reichsstelle für Eisen und Stahi 384

Reichsstelle für Elektrizitätswirschaft 382

Reichsstelle für Fette und Eier 386

Reichsstelle für Fische 386

Reichsstelle für Garten- und Weinbauerzeugnisse 386

Reichsstelle für Getreide und Futtermittel und sonstige landwirtschaftliche Erzeugnisse 386

Reichsstelle für Glas, Keramik und Holzverarbeitung 382

Reichsstelle für Hochfrequenzforschung 389. 439

Reichsstelle für Holz 368, 384

Reichsstelle für Industrielle Fette und Waschmittel 382

Reichsstelle für Kleidung und verwandie Gebiete 382

Reichsstelle für Landbeschaffung der öffentlichen Hand 348, 433

Reichsstelle für Lederwirtschaft 382

Reichsstelle für Maschinenbau 382

Reichsstelle für Milcherzeugnisse. Öle und Fette 386

Reichsstelle für Mineralöl 382

Reichsstelle für Musikbearbeitung 263

Reichsstelle für Musikbearbeitungen 262

Reichsstelle für Naturschutz 384

Reichsstelle für Papier 382

Reichsstelle für Raumordnung 265, 325, 336. 337. 348, 351

Reichsstelle für Saargut 386

Reichsstelle für Schulwesen 277

Reichsstelle fuir Sippenforschung 64

Reichsstelle für Steine und Erden 383

Reichssielle für Tabak und Kaffee 383

Reichsstelle für Technische Erzeugnisse 383

Reichsstelle für Textilwirtschaft 383

Reichsstelle für Tiere und tierische Erzeugnisse 386

Reichsstelle für Umsiedlung 384

Reichsstelle für Verpackungsmittel 383

Reichsstelle für Wirtschaftsausbau 377

Reichsstelle für Wohnungs- und Siedlungswesen 334,410

Reichsstelle zur Förderung des deutschen Schriftums 468

Reichsstifung für Länderkunde 124 
Reichsstudentenführung 456, 503, 506, 507

- Bereich West 293

Reichsstudentenwerk 282, 286, 503, 504

Reichstag 4, 58, 325, 336, 351

Reichstagsfraktion der NSDAP 473

Reichstauschstelle 267

Reichstheaterakademie 310

Reichstheaterkammer 270, 310, 320, 321

Reichstierärztekammer 167

Reichs(Sonder)treuhänder des Bekleidungsgewerbes 93

Reichs(Sonder)treuhänder für den öffentlichen Dienst 11, 411

Reichs(Sonder)treuhänder für die Heimarteit 93, 411

Reichstreuhänder der Arbeit

- Bayern 411, 513

- Bremen 74

- Franken 412

- Hessen 412

- Köln 89

- Mainfranken 412

- Niedersachsen 73, 91, 412

- Nordmark 412

- Oberbayern 412

- Schwaben 412

- Süiwest 414

- Südwestdeutschland 412, 414

- Westfalen-Niederthein 67, 83, 412

- Westmark 412

ReichstuberkuloseausschuB und -rat 167

Reichsumsiedlungsgesellschaft (Ruges) 243, 433

Reichsuniversität Posen 259. 337

Reichsuniversität StraBburg 259, 336

Reichsverband der deutschen Industrie 381

Reichsverband der Deutschen Presse 311

Reichsverband der deutschen Zeiungsverleger 311

Reichsverband der Forstsamen- und Forstpflanzenbetriebe 368

Reichsverband der Ortskrankenkassen 418

Reichsverband der Rinderzüchter Deutschlands 386

Reichsverband Deutscher Arbeitsdienstvereine e. V. 419

Reichsverband Deutscher Rentenversicherungsträger 417

Reichsverband Deutscher VerwaltungsAkademien 5, 57

Reichsverband für Volksmusik 313

Reichsverband für Zucht und Prüfung deutschen Kaltbluts 386

Reichsverein der Sippenforscher und Heraldiker bzw. für Sippenforschung und Wappenkunde 64

Reichsvereinigung Bastfaser 384
Reichsvereinigung Chemische Fasern 384

Reichsvereinigung der Juden 340, 342

Reichsvereinigung Eisen 384

Reichsvereinigung Kohle 384

Reichsvereinigung Textilveredelung 384

Reichsverkehrsdirektion Riga $\mathbf{4 0 2}$

Reichsverkehrsgruppe

- Binnenschiffahr 389

- Kraftahrgewerbe 389

- Kraftfahrzeuggewerbe 70

- Schienenbahnen 388

- Seeschiffahr 389

- Spedition und Lagerei 389

Reichsverkehrsministerium $261,368,387$, 437, 509

Reichsverkehrsrai 331

Reichsverkehrswacht 74

Reichsverlagsamt 62

Reichsversicherungsamt 252, 253, 409, 417

Reichsversicherungsanstalt für Angestellte $253,327,409,416,417$

Reichsversorgungsgericht 253

ReichsverteidigungsausschuB 66

Reichsverteidigungskommissar

- Baden 113

- Berlin 102

- im Wehrkreis V 66

- im Wehricreis VI 66

- im Wehrkaeis X 137

- im Wehrkreis XI 67

- im Wehrkreis XII 204

- Köln-Aachen 352

- Kurhessen 67.88

- Weser-Ems 67

- Westfalen-Süd 414

- Westmark 352

Reichsverteidigungsrat 428, 434

Reichsverwaltungsgericht 242, 254

Reichsverwaltungsschule Braunschweig 334

Reichswaltung der DAF 508

Reichswanderungsstelle 175

Reichswanderwan 16

Reichswehrministerium 428, 433

Reichswerk Buch und Volk 311

Reichswerke "Hermann Göring A.G. 19, $73,86,132,142,153,210,243,325,334$, $357,371,375,403,433,490$

Reichswetterdienst 3

Reichswirtschaftsgericht 243, 355

Reichswirtschaftskammer 332, 356, 379

Reichswirtschaftsministerium 261, 325, 340 , $344,355-358,361,376,381,383,396$, 407, 431

Reichswohnungskommissar 4, 336, 410

Reichszentrale für gesundheitliche Aufklärung 167 
Reichszentrale für naturwissenschaftliche Berichterstattung 306

Reichszentrale für wissenschafuliche Berichterstattung 271, 272

Reichszentralstelle für Durchführung des Vierjahresplanes in der NSDAP 462

Reichszeugmeisterei der NSDAP 463

Reinhard Heydrich Stiftung. Prag 178

Rektorenkonferenz 284, 286, 288, 295, 302

Rentenbank für die Rheinprovinz 347

Rentenbank für Pommern und SchleswigHolstein 347

Rentenbank für Sachsen und Hannover 347

Republikanischer Lehrerbund 158

Residenutheater München 320

Revolutionäre Gewerkschafts-Opposition (RGO) 59. 123

Revolutionäre Sozialisten 123

Rhein-mainisches Siedlungswerk 514

Rheinisch-westfälisches Elektrizitätswerk (RWE) 17, 209

Rheinisch-westfälisches Kohlensyndikat 33

Rheinische Friedrich-Wilhelms-Universität s. Universität Bonn

Rheinstrombauverwaltung 403

Richard-Wagner-Verband 320

Richterverein beim Reichsgericht 198

Riedel - de Haen A.G. 247

Röchling-Werke 352

Römisch-Germanische Kommission des Archäologischen Instituts des Deutschen Reiches 283

Rohstoff-Handelsgesellschaft mbH (ROGES) 364

Rotary Club 474

Rote Hilfe 83, 123, 510

Rotfrontkämpferbund (RFB) 59.68, 123

Rückwandereramt der Auslands-Organisation 472

Rüstungsinspektion

- III (Berlin) 446

- IX (Kassel) 446

- Oberthein (StraBburg) 446

- V (Stuttgar) 446

- VI (Münster) 446

- VII (München) 446

- X (Hamburg) 446

- XI (Hannover) 447

- XII (Wiesbaden) 447

- XII b (Saarbrücken) 352, 447

- XIIl (Nürnberg) 447

Rüstungskommando Augsburg 447

Rüstungskontor GmbH 364

Rüstungsobmann des Wehrkreises VIb 363

Rüstungswerk Stalowa Wola (Generalgouvernement) der Stahlwerke Braunschweig 343
Ruhrsiedlungsvertand 80

Ruhralsperrenverband 33

Rundfunkorganisation Hamburg 474

Rundfunkpolitische Abteilung des Auswärtigen Amtes 47

Ruprecht-Karls-Universität s. Universität Heidelberg

RuBland-AusschuB der deutschen Wirtschaft 381

SA (Sturmabteilungen der NSDAP) 13, 14. $31,77,83,90,92,99,113,130,134$. 143, 145, 148, 164, 207, 212, 213, 217. 218, 220, 223, 333, 434, 447, 449. 46!. 462. 463, 480, 489, 491-495, 507

- Dienst von Studenten 287, 291, 292, 296. 298, 303. 304

SA-Brigade

- 46 (Fulda) 494

- 48 (Marburg) 494

- 49 (Frankfurr) 494

- 50 (Starkenburg) 494

- 53 (Schwarzwald-Nord) 494

- 55 (Stuttgart) 495

- 56 (Schwäbisch Hall) 495

- 59 (Harz) 495

- 61 (Hannover) 495

- 65 (Detmold) 495

- 79 (Würzburg) 493

- 80 (Passau) 493

- 84 (Chiemgau) 494

- 85 (München) 494

- 86/87 (Schwaben) 494

- 146 (Melsungen) 494

- 153 (Heidelberg) 495

SA-Brigaden 72, 73, 74, 75, 76, 110 und 169495

SA-Gruppe

- Bayerische Ostmark 492. 493

- Franken 492. 493

- Hansa Hamburg 493

- Hessen 494

- Hochland 492, 494

- Kurpfalz 494

- Mittelmein (Wesumark) 495

- Niederrhein 495

- Niedersachsen 495

- Nordsee 495

- Südwest 495

- Westfalen 495

SA-Gruppenschule Fredeburg 495

SA-Hilfswerklager 87, 495

SA-Hochschulämier 271, 284, 286, 289, 290. 291. 294, 296, 305

SA-Jägerstandarten 3 (Traunstein) und 5 (Garching) 494

SA-Lager Hochkreuz, Porz-Eil 205, 221 
SA-Reiterstandarte 50494

SA-Reilerstandaren 55 und 155495

SA-Sonderbeaufuragte für Füssen und Krumbach 494

SA-Standarte "Feldherrnhalle" 492

SA-Standare

- 5 (Bamberg) 493

- 7 (Bayreuth) 493

- J 8 (Würselen) 495

- 10 (Ingolstadt) 493

- 15 (Bottrop) 495

- 16 (Köln) 495

- 17 (Helmstedt) 495

- 25 (Aachen) 495

- 28 (Hof) 493

- 32 (Zwiesel) 493

- 53 (Solingen) 495

- 79 (Hildesheim) 495

- 82 (Göttingen) 495

- 109 (Karlsruhe) 494

- 110 (Heidelberg) 494

- 111 (Rastatt) 494

- 112 (Eberbach) 494

- 115494

- 130 (Siegen) 495

- 136 (Köln) 495

- 143 (Recklinghausen) 495

- 145494

- 160 (Bonn) 495

- 161 (Düren) 495

- 168494

- 221494

- 222 (Friedberg) 494

- 250 (Bruchsal) 494

- 390494

- 457 (Herne) 495

- 471 (Dülmen) 495

SA-Wehrmannschaft 491, 492

Saalburgmuseum Bad Homburg 338

Saarbergwerke 352

Saarbevollmächtigter der Reichsregierung 7

Sachbearbeiter für alle Fragen der Volksgesundheit 459

Sachverständiger für Rassenforschung beim Reichsministerium des Innern 64

Sachverständiger für Rassenforschung, oldenburg. 18

Sanitätsabteilung der 7. Infanteriedivision 450

Sanitätsamt der SS 117,118

Schauspielhaus Berlin 319

Scheinwerferregimenter Nr. 2, 3, 74, und 611452

Schering A. G. 247

Schlesisches Institut Kattowitz 178

Schnelldampfer .Bremen“ 142
Schriftleitung des .Deutschen Kulturdienstes" 318

Schul- und Hochschulabteilung Hamburg 25 Schul- und Kultusverwaltung Lübeck 271

Schulungsamt der SS 117

Schulungslager Hankensbüttel der Forstverwaltung 91

Schutzhaftlager Benninghausen/Krs. Lippstadt 128

Schutzhaftlager Eutin 128

Schulzhafuager Kislau 15, 129

Schutzhafuager Moringen/Krs. Northeim 129

Schutzpolizei-Dienstabteilung Aschaffenburg 152, 152

Schwäbischer Sängerbund 313

Schwarze Front 78, 143

Schwesternversicherungsverein des DRK 168 SD 45, 56, 92, 119, 121, 122, 125, 139.

140, 156-160, 286, 462, 509

SD-Abschnitt

- Aachen 156

- Augsburg 156

- Bayreuth 156

- Bielefeld 157

- Bremen 157

- Darmstadi 142, 157

- Dortmund 157

- Frankfurt 139, 158, 482

- Karisruhe 158

- Kiel 159

- Koblenz 139. 159

- Köln 159

- Nürnberg 160

- Würtemberg-Hohenzollern 160

- XI 160

SD-AuBenstelle

- Aschaffenburg 158

- Bad Brückenau 160

- Bad Kissingen 160

- Bad Kreuznach 159

- Bad Neustadu/Saale 160

- Berchtesgaden 159

- Birkenfeld 159

- Cochem 159

- Ebern 160

- Friedberg 156

- Gelsenkirchen-Buer 157

- Heilbronn 160

- Karlstadt 160

- Kitzingen 160

- Koblenz 159

- Königshofen 160

- Lohr 160

- Mainz 159

- Marburg 158

- Marktheidenfeld 160

- Monschau 156 
SD-Aubenstelle (Fors.)

- Neuwied 159

- Oldenburg 157

- Passau 157

- Schweinfur 160

- Sigmaringen 160

- Stuttgar 160

- Trier 159

- Wetzlar 158

- Würzburg (1939-1944) 160

SD-Fürer Baden-ElsaB 158

SD-Hauptamt 122, 123. 160

SD-HauptauBenstelle

- Freiburg 158

- Hannover 158

- Kassel 158, 158

- Mannheim 158

- Wiesbaden 160

- Würzburg 160

SD-Leitabschnitt

- Düsseidorf 157

- München 159, 160

- Stutgart 160

SD-Oberabschnitt

- Fulda-Werra 158, 159

- Rhein 157, 159

- Südwest 158, 160

SD-Schule Bernau 125, 157

SD-Unterabschnitt

- Baden 158

- Hessen 157

- Wiesbaden 160

Seeam!

- Bremethaven 248

- Emden 29. 248

- Hamburg 29, 248

Seeberufsgenossenschaft 393

Seedienst OsıpreuBen 372

Seedisziplinathof 256

Seedisziplinarkammern Bremerhaven, Danzig. Fensburg, Hamburg und Stettin 256. 257

Seefahrtschule Elsfleth 270

Seehandlung (PreuBische Slaatsbank) 347

Seekasse 417

Seekriegsleitung 436

SeerechtsausschuB der ADR 182

Seeschiffahrtsamt 37 !

Sektion für deutsche Staats- und Wirtschaftskunde der Deutschen Akademie 314

Seminar für arische Sprach- und Kulturwissenschaften 295

Seminar für orientalische Sprachen 280

Seminar für rassenkundliche Geistesgeschichte 290

Seminar fur Staatswissenschaft 282

Senator für das Bauwesen, Bremen 353
Senator für Häfen. Schiffahrt und Verkehr, Bremen 392

Senatskanzlei Bremen 25

Senatskanzlei Hamburg 24

Senatskanzlei Lübeck 26

Senatskommission für die Justizverwaltung. Hamburg 185

Senatskommission für die Kunstpflege. Hamburg 308

Senatskommission für die Reichs- und auswärtigen Angelegenheiten, Hamburg 23

Senckenbergische Naturforschende Gesellschaft 283

Sender „Hans Weber" 317

Sender .SA-Mann Max Schröder" 317

Sender Belgrad 48

Sicherheitshauptamt der SS 122, 123, 160

Sichenungsanstalt

- Butzbach 191

- Rendsburg 196

- Straubing 196

- Wer 197

Sicherungsdivision, 5. 236

Sicherungslager Vorbruck-Schirmeck 133 , 135. 336

Siedlungsamt der SS 119

Siedlungsgemeinschaft, -gesellschaft ..Bauernland" 217,245

Siemens A.G. 437

Sippenämter Nordfriesland, Dithmarschen, Lauenburg. Wagrien 75

Sippenamt der SS 119

Sippenamt Emden 103

Sippenkanzlei der Arbeitsgemeinschaft der Optanten 64

Sippenstelle der Landesbauernschaft WeserEms 401

Sippenstelle für das Land Oldenburg 270

SonderausschuB Eisenbahnwagen des Hauptausschusses Schienenfahrzeuge 387

Sonderbeauftragter der Deutschen Reichspost in Spanien 387

Sonderbeauftragter des Reichsverkehrsministeriums für Ausweichwerke 387

Sonderbeaufuragter fuir Anbau von Pflanzenkautschuk 115

Sonderbeauftragter für die Überprüfung des zweckmäBigen Kriegseinsatzes 432

Sonderbevollmächtigter für die Erdölwirtschaft 55

Sonderdienst Landhaus 317

Sonderdienst Seehaus 263, 317

Sondergericht

- Aachen 229

- Altona 229

- Bamberg 194, 229 
Sondergericht (Forts.)

- Bayreuth 230

- Berlin 230

- Bielefeld 230

- Braunschweig 230

- Bremen 230

- Bromberg 195

- Danzig 195

- Darmstadt 230

- der Obersten SA.Führung 492. 493

- Dorumund 216, 231

- Düsseldorf 230

- Duisburg 230

- Elbing 195

- Erfurt 195

- Essen 231

- Frankfurt 231

- Freiburg 219, 231

- Graudenz 195

- Hagen 231

- Halle 194

- Hamburg 198, 229, 230, 231

- Hannover 220, 224, 231

- Kassel 220, 231

- Kiel 229, 232

- Koblenz 232

- Köln 232

- Königsberg 194

- Mannheim 232

- München 232

- Nürnberg 233

- Oldenburg 213, 233

- Rostock 195

- Saarbrücken 233

- Schwerin 195

- Stuttgart 220, 233

- Wien 196

- Würzburg 233

- Wuppertal 234

Sonderkommando zur Erforschung der Geschichte der Hexenverfolgung 125

Sopade 123

Sozialbehörde Hamburg 24

Sozialgewerk Bremer Handwerker 515

Sozialistische Arbeiter- und Jugendinternationale 123

Sozialistische Arbeiterjugend (SAJ) 59

Sozialistische Asteiterpartei (SAP) 59, 123, 158

Sozialistische Front 123

Soziographisches Institut 283

Spargemeinschaft SS e. V. 163

Sparkassen- und Giroverband, Rhein. 79

SPD 4, 14, 17, 26, 59, 68, 72, 84, 90, 92 , $111,122,123,142,143,144,147,148$. $149,150,154,158,159,184,232,244$. $248,256,289,330,334,347,474,510$
Spielgemeinschaft für nationale Festgestaltung 399

SS (Schutzstaffel der NSDAP) 14, 44, 72. $80,83,98,100,104,114-126,128-138$. 159, 162-164, 173, 180, 237, 238. 256. 268, 296. 303. 325. 334, 400, 433. 449. 462. 463

SS- und Polizeigericht

- I. München 238

- II. Düsseldorf 238

- III. Berlin 238

- XI. Stungart 238

- XI1. Hamburg 238

- XIV. Wiesbaden 238

- XXV. Nürnberg 238

- XXVI, Braunschweig 238

- z. b. V., Kassel 238

SS-Abschnitt

- V 164

- IX 163

$-X 164$

- XIV 163

- XV 163

- XVII 164

- XIX 164

- XXIII 164

- XXVIII 163

- XXX 162

- XXXII 164

SS-Amt Reit- und Fahrwesen 118

SS-Brigade Dirlewanger 117

SS-Führer im Rasse- und Siedlungswesen

Rhein 138

SS-Fürsorgekommando Fulda-Werra 137

SS-Fürsorgekommando Süd 137

SS-Genesendenbataillon Wesserling/ElsaB 117

SS-Hauptamt Haushalt und Bauten 120

SS-Higa-Sturmbann Main 163

SS-Junkerschule Bad Tölz 136, 433

SS-Junkerschule Braunschweig 136, 334

SS-Kriegsberichter-Abteilung .Kun Eggers“ 238

SS-Lazarett Hohenlychen 114

SS-Leibstandarte.Adolf Hitler 135

SS-Motorstandarte 2163

SS-Motorstandarte 9163

SS-Motorstandarte Arolsen 162

SS-Musikschule Braunschweig 19

SS-Nachrichten-Ersalzregiment Nürnberg 238

SS-Nachrichtensturmbann 3162

SS-Nebelabteilung Obersalzberg 451

SS-Oberabschnit

- Fulda-Werta 162

- Main 163, 164

- Mitte 163

- Nordsee 163 
SS-Oberabschnitt (Forts.)

- Nordwest 163

- Rhein-Westmark 164

- Rhein 159, 162,163

- Spree 164

- Süd 163, 164

- Südwest 164

- West 164

SS-Pflegestellen bei den SS-Standarten 120

SS-Reiterstandarte 17 (Regensburg) und SS-

Reiterstandarte 24163

SS-Reiterstandarte 21163

SS-Reiterstandarte Arolsen 162

SS-Reitschule Hannover 84

SS-Richter beim Reichsführer SS 238

SS-Sanitätsabteilung Nürnberg 163

SS-Schule St. Georgen/Schwarzwald 164

SS-Sonderkommando K(aukasus) 276

SS-Sonderlager Hinzer 132

SS-Standarte

- 6164

$-13164$

$-15164$

$-17163$

- 20164

- 25164

- 28163

- 32164

- 33163

- 34164

- 35162

- 41163

- 44164

- 56163

- 58164

$-62164$

- 68163

- 78163

- 79164

- 80164

- 81163,164

- 83162,163

$-85164$

- 88163

SS-Standonart Flossenbürg 131

SS-Totenkopfstandarten 135

SS-Totenkopfsturmbann

- Auschwitz 136

- Buchenwald 137

- Dachau 131

- Flossenbürg 131

- Lublin-Majdanek 136

- Mauthausen 136

- Natzweiler 136

- Sachsenhausen 136

SS-Wirtschaftsverwaltungshauptamt, Amtsgruppe D 127
Staatliche Beratungsstelle für das Volksbüchereiwesen Hannover 30

Staatliche Museen Berlin 338

Staatliche Pressestelle Hamburg 308

Staatsamt Bremen 26

Staatsamt Hamburg 24

Staatsanwaltschaft beim Landgericht (auch Sondergericht)

- Aachen 216

- Altona 216

- Amberg 216

- Ansbach 216

- Arnsberg 216. 231

- Aschaffenburg 216

- Augsburg 216

- Aurich 217

- Berlin 217

- Bielefeld 217

- Bochum 217

- Bonn 217

- Braunschweig 230

- Bremen 217

- Bückeburg 217

- Darmstadt 218

- Deggendorf 218

- Detmold 19, 218

- Dortunund 218

- Düsseldorf 218

- Duisburg 218

- Eichstätt 218

- Essen 218, 257

- Flensburg 219

- Frankenthal 219

- Frankfun 219

- Freiburg 205, 219

- Göttingen 219

- Hagen 219

- Hanau 219

- Hannover 220

- Hechingen 220

- Heidelberg 205, 220

- Hildesheim 220

- Hof 220

- Itzehoe 220

- Kaiserslautern 220

- Karlsruhe. Zweigstelle Pforzheim 224

- Karlsruhe 205. 220

- Kassel 220

- Kempten 221

- Kiel 221

- Kleve 221

- Koblenz 221

- Köln 130, 148, 221

- Konstanz 205. 221

- Krefeld 221

- Landau 222

- Landshut 222 
Staatsanwaltschaft beim Landgericht (Fors.)

- Limburg 222

- Lübeck 222

- Lüneburg 222

- Mannheim 205, 222

- Marburg 222

- Mernmingen 222

- Mönchengladbach 223

- Mosbach 205

- München I 223

- München II 223

- Münster 223

- Nürnberg-Furth 223

- Offenburg 205. 223

- Oldenburg 223. 233

- Osnabrïck 224

- Paderborn 224

- Passau 224

- Regensburg 224

- Rottweil 224

- Stade 224

- Stuttgart 224

- Traunstein 225

- Trier 225, 232

- Tübingen 225

- Ulm 225

- Verden 225

- Waldshut 205. 225

- Weiden 225

- Wiesbaden 226

- Würzburg 226

- Wuppertal 226

- Zweibrücken 226

Staatsanwaltschaft beim Oberlandesgericht

- Bamberg 203

- Braunschweig 203

- Celle 203

- Darmstadi 204

- Düsseldorf 204, 221

- Frankfurt 205

- Hamburg 204

- Hamm 204. 519

- Karlsruhe 205

- Kiel 205

- Köln 205

- München 205

- Nürnberg 206

- Oldenburg 206, 233

- Zweibrücken 206

Staatsarchive Marburg und Münster 337

Staatsbank. Braunschweigische 334

Staatsbank. PreuBische 338, 347

Staatsbauamt Lingen 190

Staatsbibliothek, preuB. 266

Staatsgemäldesammlungen, bayer. 268

Staatshauptkasse Bremen 335

Staatskanzlei, bayer. 13, 149
Staatskommissar bei der Börse Köln 90

Staatskommissar für Arbeits- und Mittelstandsfragen. hess. 18

Staatskommissar für die Deutsche Schauspielhaus AG und Neue Schauspielhaus GmbH Hamburg 23

Staatskornmissar für Landwirschaft, hess. 18

Staatskommissar für Oldenburg 18

Staatsmedizinische Akademie, bayer. 294

Staatsministerium Baden 15

Staatsministerium Braunschweig 18, 73, 76. 307

Staatsministerium Oldenburg 18

Staatsministerium PreuBen 11-13. 329, 358. 407

Staatsministerium Würtemberg 14

Staatsmusikschule Braunschweig 27 !

Staatsoper Berlin 319, 338

Staatsoper München 320

Staatspolizej-AuBenstelle

- Bochum 143

- Duisburg 143, 144

- Essen 143, 144

- GieBen 142

- Hagen 143

- Hamm 143

- Heide 147

- Krefeld 143, 144

- Mönchengladbach 143

- Oberhausen 143

- Offenbach 142

- Paderborn 141

- Siegen 143

- Wiesbaden 144

- Wupperal 143. 144

Staatspolizei-Sonderkommando Kütter 148 Staatspolizei(leit)stelle

- Aachen 78, 140

- Altona 140

- Augsburg 140, 141

- Berlin 141

- Bielefeld 20, 140, 141, 154

- Braunschweig 142, 153

- Bremen 142, 153. 154

- Darmstadt 139, 142, 153

- Dortmund 80, 140, 143, 154

- Düsseldorf 83, 143, 153, 177

- FrankfurtMain 144, 153

- Hamburg 145, 342

- Hannover 142, 145

- Harburg-Wilhelmsburg 140

- Hildesheim 145

- Karlsruhe 139, 146

- Kassel 87, 146, 153

- Kiel 147. 154

- Koblenz 88. 147

- Köln 137, 147, 443 
Staatspolizei(leit)stelle (Forts.)

- Lübeck 27

- Lüneburg 91, 148

- München 139, 148

- Münster 149

- NeustadrNeinstraBe 149

- Nürnberg 150

- Osnabrück 95. 140, 142. 150

- Recklinghausen 140. 149

- Regensburg 150

- Saarbrücken 151

- Sigmaringen 151

- Stuttgart 139, 151, 154, 339

- Trier 100, 151, 197. 443

- Weimar 153

- Wesermünde 140

- Withelmshaven 140, 152

- Würzburg 140, 152, 160

Slaatsrat preuB. 329, 508

Staatsschuldenverwaltung Hamburg 341

Staatsschuldenverwaltung, preuB. 327. 329

Staatstheater Kassel 338

Staatstheater Oldenburg 321

Staatstheater, bad. 320

Staatstheater. bayer. 320,338

Staatstheater, preuB. 12, 338

Staatsunterstützungskasse, hess. 18

Staatsverwaltung Hamburg 23

Staatswirtschaftliches Seminar 294

Stab des Stellvertreters des Führers 457, 458

Stabsamt Göring 11

Stadtbauburo der DAF in der Stadt des KdF.

Wagens 511

Stadipräsident der Reichshauptstadt 102

Stadiverwaltung Berlin 247, 349

Stadiverwaltung Papenburg 150, 190

Stadtverwaltungsgericht Lübeck 246

Stahlhelm - Bund der Frontsoldaten 5. 14.

$78,90,123,143,247,407,419,421,422$. $423,424,425,492$

Stahlwerke Braunschweig 343

Standard Oil Company (Esso) 188

Standgericht des Kommandierenden Generals im Luftgau XIV 237

Statistisch-wissenschafuliches Institut des

Reichsführers SS 116

Statistisches Amt Braunschweig 394

Statistisches Amt Saariand 394

Statistisches Landesami Hamburg 394

Statistisches Landesamt PreuBen 68

Statistisches Landesamt Wüntemberg 393

Statistisches Reichsamt 178, 366, 376

Steinwerke Oranienburg 349

Stellvertreter des Führers 456, 466, 470, 475. 478

Steuerverwaltung Hamburg 342
Steyler Missionare (Societas verbi divini)

218, 340

Stiftung .Arbeitsdank" 341. 424

Stiftung .Preußenhaus" 12. 13

Stiftung Externsteine 115

Stifung für Opfer der Arbeit 5

Stiftung Schorfheide 329

Stiftung zur Erforschung des deutschen

Volkstums im Süden und Südosten 294

Strafanstalt Dresden 227

Strafgefangenenlager Brual-Rhede 224

Strafgefangenenlager Emsland 181, 189, 192. 197. 203. 213. 394

Strafrechts- und StrafprozeBkommission 180

Studentenring Hamburg 506

Studienstiftung St. Paul in Regensburg 106

Sudetendeutscher Heimatbund 298

Süddeutscher Rundfunk 339

Südostdeutsche Forschungsgemeinschaft 178

Südosteuropa-Gesellschaft 49

Sven-Hedin-Institut 294

T 4. Dienststelle Tiergartenstraße 4 der Kanzlei des Führers 457

Tannenbergbund 78.90

Technikum Lage (Lippe) 20

Technische Akademie der Luftwaffe. BerlinGatow 438

Technische Führerschule München des NSKK 496

Technische Hochschule

- Aachen 36, 78. 266. 300, 337. 505

- Berlin 266. 301. 337

- Braunschweig 271, 301, 307, 334

- Breslau 266

- Brünn 337

- Darmstadt 17. 302. 337

- Hannover 31. 266. 302, 337. 506

- Karlsruhe 269. 303

- München 267. 300

- Stuttgart 15, 303. 337. 339

Technische Nothilfe. Gruppenleitung Berlin 126

Theater am Gärtnerplatz, München 320

Theaterzug Weser-Ems 321

Theologische Arbeitsgemeinschaft 281

Theosophische Geselischaft 83

Tieräztliche Hochschule Hannover 31, 266. 337

Tierärztliches Bezirksgericht Hannover 29

Transporteinheiten Todu/Speer 349.412

Transponflotte Speer 351, 364

Transportstandarte Speer 351, 364

Treuhänder für Textilrohstoffe 359

Treuhandgeselischaft $1933 \mathrm{mbH} 345,346$

Treuhandgesellschaft für die wirtschafilichen Unternehmungen der DAF 511 
Truppenamt des Reichswehrministeriums 433 Truppenübungsplacz Grafenwöhr 105

Ufa - Universum Film A.G 262, 264, 319

Ufa-Film-GmbH (Ufi) 318

Umschuldungsverband deutscher Gemeinden 327. 347

Unilever-Konzern 360

Union-Club 148

Universität

- Basel 283

- Berlin 266. 275, 280. 337. 350. 353

- Bonn 36, 159, 191, 266, 280, 337

- Breslau 266, 337

- Erlangen 267, 281

- Frankfurt 266, 282, 506

- Freiburg 269, 283, 337

- Gieben 17, 285. 506

- Göttingen 31, 266. 286. 337

- Greifswald 266, 337

- Halle 266, 337

- Hamburg 25, 287. 506

- Heidelberg 269, 288, 306

- Jena 337, 467

- Kiel 266, 290, 337. 506, 508

- Köln 266, 290, 506, 508

- Königsberg 266, 337

- Marburg 266, 293, 337. 508

- München 267, 294, 337

- Münster 34, 266, 295, 337

- Posen 259, 337

- Rostock 337

- StraBburg 259, 283, 336

- Tübingen 297, 444, 507. 508

- Würzburg 267. 299. 507

Unjversitätsbibliothek StraBburg 285

Universitätsgesellschaft Kiel 290

Unterstützungsverein der in der modernen Arbeiterbewegung tätigen Angestellten 244

Untersuchungs- und SchlichtungsausschuB der NSDAP 471

Untersuchungsstelle für Nahrungs- und GenuBmittel, KasseI 88

Varieté-Schiedsgericht 310

Vaterländischer Frauenverein 502

Vera-Verlag 465

Verbindungsoffizier zum Reichswirtschaftsministerium 431

Verbindungsstelle Berlin, schleswigholsteinische 28

Verein der Eisenhüttenleute 523

Verein deutscher Chemiker 523

Verein deutscher Eisenbahnverwaltungen 387

Verein deutscher Ingenieure 523

Verein deutsches Jugendwerk 148

Verein für Arbeitsdienst „Westküste“ 421
Verein für das Deutschtum im Ausland (VDA) 175. 177. 472

Verein mitteleuropäischer Eisenbahnverwaltungen 369

Vereinigte Industrieunternehmen A.G. (VIAG-Konzern) 336

Vereinigte Studienstiftsverwaltung Heidelberg 289

Vereinigung Carl Schurz e. V. 173

Vereinigung der .Naturfreunde* 20. 244

Vereinigung der Berufssippenforscher e.V. 65

Vereinigung der Freunde der Universität Tübingen 299

Vereinigung der Verleger für Volksliteratur 311

Vereinigung Holzhaltig/Holzfrei 382

Vereinigung von Freunden der Technischen Hochschule Stuttgart 303

Verkehrsbeauftragter für die Wirtschaft im Bezirk der Reichsbahndirektion Essen 397

Verkehrswissenschaftlicher Forschungsrat 372, 387

Vermittlung Innsbruck für Südtiroler Optanten 174

Vermögens- und Schuldenverwaltung, bremische 335

Vermögensverwertungsstelle Hamburg 342

Versicherungsanstait für gemeindliche Beamte. hess. 75

Versorgunigs- und Fürsorgeamt der SS 117

Versorgungsamt Essen 419

Versorgungsami Köln 419

Versuchs- und Forschungsanstalt für alpine Landwirtschaft. Admont 365

Versuchs- und Forschungsanstait für Fleischwirtschafi 365

Versuchs- und Forschungsanstalt für Getreidewirtschaft, Berlin 365

Versuchs- und Forschungsanstalt für Kleintierzucht, Celle 365

Versuchs- und Forschungsanstalt für Landarbeit. Bornim 365

Versuchs- und Forschungsanstalt für Milchwirtschaft, Kiel 365

Versuchs- und Forschungsanstalt für Schweinehaltung, Ruhlsdorf 365

Versuchs- und Forschungsanstalt für Tabakforschung. Forchheim 365

Versuchs- und Forschungsanstalt für Tierzucht, Kraftborn 365

Versuchs- und Forschungsanstalt für Weinund Gartenbau, Geisenheim 365

Versuchs- und Forschungsanstalten für Landwirtschaft, Bromberg. Säusenstein, Landsberg/Warthe, Wien 365

Versuchsanstalt für Getreideverarbeitung GmbH. preuB. 385 
Versuchsanstalt Peenemünde $\mathbf{4 0 8}$

Verureter der Obersten Dienstbehörde beim Reichsdienststrafhof 254

Vertretung Braunschweigs in Bertin 19

Vertretung Hessens in Berlin 18

Venretung Lübecks bei der Reichsregierung 27

Verwaltung für Wirtschaft. Technik und Arbeit, Hamburg 392

Verwaltung Obersalzberg 458

Verwaltungs- und Verwertungsgesellschaft Lodz 359

Verwaltungsakademie, badische 269

Verwaltungsamt der SS 117. 120

Verwaltungsgericht

- Berlin 102

- Bremen 246

- Lübeck 246

Verwaltungsgerichtshof, bad. 15

Verwaltungsgerichtshof, bayer. 242

Verwaltungsgerichtshof, braunschw. 72

Verwaltungsgerichishof. sächs. 242

Verwaltungsgerichtshof. würtiemberg. 245

Verwaltungsrat der Deutschen Reichsbahn 369

Verwaltungsrat der Deutschen Reichspost 53. 373

Viehwirtschaftsstelle Westfalen 398

Viehwirtschaftsverband

- Hannover 398

- Kurhessen 399

- Schleswig-Holstein 398

Vikıoria-Luise-Bund 84

Villa Massimo in Rom 338

Vineta. Propagandadienst Ostraum e. V. 263

Vizekanzlei von Papen 4, 6

Volksbühne. Berlin 338

Volksbund für das Deutschium im Ausland 186

Volksbund sippenkundlicher Vereine 64

Volksdeutsche Bewegung in Luxemburg 83

Volksdeutsche Bewegung in Ungarn 12

Volksdeutsche Mittelstelle 44, 61, 160, 174, 177

Volksgerichtshof 8, 142.180, 181, 182. 197. 226. 464

Volkspflegeschule 86

Volkstumsbüro des Stellvertreters des Führers 174

Volksverein für das katholische Deutschland 244

Volkswagenwerk 19,91, 27!, 433

Vulkanwerft, Stettin 511

Waffenami der SS 118

Waffenkommissionen 434
Waldlager $\mathrm{V}$ des Konzentrationslagers

Dachau 131

Walker-Rathenau-Stiftung 58

Wannsee-Institut 124

Wasgenwaldbahn 344

Wasser- und Schiffahrsdirektion Freiburg 333. 403

Wasser- und Schiffahrtsverwaltung Aurich 82

Wasserbautechnische Abteilung des Reichsverkehrsministeriums 371

Wasserstraßenamt Braunschweig 403

WasserstraBendirektion

- Bremen 403

- Hamburg 23

- Hannover 403

- Kiel 403

- Koblenz 403

- Münster 403

Wasserwirschaftsamt Meppen 394

Wehrgeistiger Führungsstab im Allgemeinen Marinehauptamı 436

Wehrkreisbücherei $V 444$

Wehrkreisprosektur am Pathologischen Institut Tübingen 444

Wehrmacht-Fürsorge- und Versorgungsamt München-Landshut 448

Wehrmacht-Untersuchungsstelle für Verletzungen des Völkerrechts 428

Wehrmachtauskunftsielle für Kriegerverluste und Kriegsgefangene (WASt) 65. 432

Wehrmachtführungsamt 429

Wehrmachtführungsstab. Abteilung Wehrmachtpropaganda 429

Wehrmachtfürsorge- und Versorgungsabteilung des OKW 430

Wehrmachtkommandantur

- Berlin 237

- Düsseldorf 237

- Hamburg 237

- München 444

- Würzburg 444

Wehrmachtrechtsabteilung im OKW 428

Wehrmachtversorgungsgruppe VIl (München) 448

Wehrmachtverwaltungsabteilung im OKW 431

Wehrpolitisches Am: der NSDAP 8. 470

Wehrtechnische Fakultät Berlin 266

Wehrwinschaftliche Abteilung des Reichswirtschaftsministeriums für den Wehrwirtschaftsbezirk V 396

Wehrwirtschaftliche Forschungsstelle Berlin 291

Wehrwirtschafts- und Rüstungsamt im OKW 431. 440

Wehrwirtschaftsstab 431

Weltbild GmbH 318 
Weltpostverein 373

Werberat der Deutschen Wirtschaft 262, 308. 315

Werkschulen der Reichsbahn 388

Wertpapierstelle der Reichshauptkasse 327

Westdeutsche Forschungsgemeinschaft 269

Westdeutsche Kreditgenossenschaft 223

Westfälische Wilhelms-Universität s. Universitäl Münster

Westfälisches Arbeitsdienstwerk 422

Wetterbezirkszentrale Berlin-Tempelhof 439

Winterhilfswerk (WHW) 22, 73, 76, 77, 79. 93. 96. 264. 316. 320. 390, 431, 473. 515. 516,517

Wintershall A.G. 214

Wirtschaftiche Forschungsgesellschaft (Wifo) 375,384

Wirtschafts- und Verkehrsverwaltung Bremen 392

Wirtschafts- und Verkehrsverwaltung Hamburg 392

Wirtschafts-StraBentransportienst Ost 360

Wirtschafts-Verwaltungshauptamt der SS (WVHA) 120

Wirtschaftsenator Bremen 393

Wirtschaftsgruppe

- Bauindustrie 381

- Bekleidungsindustrie 381

- Brauerei und Mälzerei 381

- Chemische Industrie 381

- Druck 381

- Einzelhandel 380. 382

- Eisen-. Stahl- und Blechwarenindustrie 381

- Eisenschaffende Industrie 381

- Elektrizitätsversorgung 382

- Elektroindustrie 381

- Fahrzeugindustrie 381

- Feinmechanik und Optik 381

- Gas- und Wasserversorgung 382

- Gemeinschaftseinkauf 382

- GieBereiindustrie 381

- Glasindustrie 381

- GroB- und AuBenhandel 382

- Holzverarbeitende Industrie 381

- Keramische Industrie 381

- Kraftstoffindustrie 381

- Lebensmittelindustrie 381

- Lederindustrie 381

- Luftfahrtindustrie 381

- Maschinenbau 381

- Metallindustrie 381

- Papier-. Pappen-. Zellstoff- und Holzstofferzeugung 381

- Papierverarbeitung 381

- Privates Bankgewerbe 382

- Sägeindustrie 381
Wirtschaftsgruppe (Forts.)

- Stahl- und Eisenbau 381

- Steine und Erden 381

- Textilindustrie 381

- Unfall-. Rück- und Kredit-. Haftpflichtversicherung 380

- Vermittlergewerbe 382

Winschaftsministerium. bad. 331

Wirtschaftsministerium. bayer. 390. 396

Wirtschaftsministerium, württemberg. 360 . 391, 398

Wirtschaftswerbedienst GmbH 315

Württembergische Gesellschaft zur Förderung der Wissenschaften 299

Zentralarchiv der Deutschen Arbeitsfront 512

Zentralaufsichtsstelle für Sprengstoff- und Munitionsfabriken 410

Zentralbauleitungen der SS 120

Zentralbodenamt 174

Zentraldirektion der Monumenta Germaniae historica 274

Zentrale Planung im Vierjahresplan 361

Zentralfilmgesellschaft Ost 264

Zentralgericht des Heeres 235

Zentralhandelsgesellschaft Ost für landwirschaftlichen Absatz und Bedarf $\mathrm{mbH}$. (ZHO) 55

Zentralkommission für die Rheinschiffahn 101. 332. 371

Zentralleitung für das Stiftungs- und Anstaltswesen. württemberg. 77

Zentralnachweiseamt für Kriegerverluste und Kriegergräber 65

Zentralsekretariat des Beauftragten für den Vierjahresplan 358

Zentralstaatsanwaltschaft Berlin 204

Zentraistelle für deutsche Kulturfunksendungen ins Ausland 263

Zentralstelle für die Finanzwirtschaft der DAF 510

Zentralstelle für Nachkriegsgeschichte 12. 337

Zentralstelle für ostfriesische Sippenforschung 82

Zentralstelle für Telegramme Berlin 408

Zentralzeugamt der SS 118

Zentrum 4.142. 143.157. 160

Zerstörergeschwader Nr. 26451

Zollfahndungsstelle Hamburg 342

Zollfahndungsstelle Saarbrücken 343

Zuchthaus

- Amberg 190

- Berlin-Plötzensee 181

- Brandenburg-Görden 180

- Bremen-Oslebshausen 191

- Bruchsal 191 
Zuchthaus (Forts.)

- Celle 222

- Ebrach 192

- Kaisheim 193

- Kassel-Wehlheiden 193

- Ludwigsburg 195

- Münster 195

- Remscheid-Lüttringhausen 195

- Rheinbach 166, 196

- Rockenberg 196

- Siegburg 196

Zuckerwirtschaftsverband Hannover 398

Zusaizversorgungsanstalt des Reichs und der Länder 326

Zweckverband Reichsparteilag 46I
Zweigstelle den Haag der Betriebskrankenkasse des Reichs 418

Zweigstelle Erdöl des Reichsamtes für Bodenforschung 378

Zweigstelle Naumburg der Biologischen Reichsanstalt 385

Zweigstelle Pfalz (für die bayerischen Angelegenheiten) des Oberinanzpräsidenten Westmark 344

Zweigstelle Pforzheim der Staatsanwaltschaft beim Landgericht Karisnuhe 224

Zweigstelle Trier des Sondergerichts Koblenz 232

Zweigstellen Koblenz und Köln der Betriebskrankenkasse des Reichs 418 